\title{
Altered protein prenylation in Sertoli cells is associated with adult infertility resulting from childhood mumps infection
}

\author{
Xiu-Xing Wang, ${ }^{1}$ Pu Ying, ${ }^{1}$ Fan Diao, ${ }^{1}$ Qiang Wang, ${ }^{1}$ Dan Ye, ${ }^{1}$ \\ Chen Jiang, ${ }^{1}$ Ning Shen, ${ }^{1} \mathrm{Na} \mathrm{Xu},{ }^{1}$ Wei-Bo Chen, ${ }^{1}$ Shan-Shan Lai, ${ }^{1}$ \\ Shan Jiang, ${ }^{1}$ Xiao-Li Miao, ${ }^{2}$ Jin Feng, ${ }^{2}$ Wei-Wei Tao, ${ }^{1}$ Ning-Wei Zhao, ${ }^{5}$ \\ Bing Yao, ${ }^{1}$ Zhi-Peng Xu, ${ }^{1}$ Hai-Xiang Sun, ${ }^{1}$ Jian-Min Li, ${ }^{3}$ Jia-Hao Sha, ${ }^{3}$ \\ Xing-Xu Huang, ${ }^{1}$ Qing-Hua Shi, ${ }^{4}$ Hong Tang, ${ }^{2}$ Xiang Gao, ${ }^{1}$ and Chao-Jun Li ${ }^{1}$ \\ 'MOE Key Laboratory of Model Animals for Disease Study, Model Animal Research Center and Jiangsu Key Laboratory \\ of Molecular Medicine of the School of Medicine, Nanjing University, National Resource Center for Mutant Mice, Nanjing \\ 210061, China \\ ${ }^{2}$ Center for Infection and Immunity and National Laboratory of Biomacromolecules, Institute of Biophysics, Chinese Academy \\ of Sciences, Beijing 100101, China \\ ${ }^{3}$ State Key Laboratory of Reproductive Medicine, Nanjing Medical University, Nanjing 210029, China \\ ${ }^{4}$ Hefei National Laboratory for Physical Sciences at the Microscale and School of Life Sciences, University of Science \\ and Technology of China, Hefei 230027, China \\ ${ }^{5}$ Department of Life Science and Clinical Medicine, Shimadzu (China) Co., Ltd., Shanghai 200052, China
}

Mumps commonly affects children 5-9 yr of age, and can lead to permanent adult sterility in certain cases. However, the etiology of this long-term effect remains unclear. Mumps infection results in progressive degeneration of the seminiferous epithelium and, occasionally, Sertoli cell-only syndrome. Thus, the remaining Sertoli cells may be critical to spermatogenesis recovery after orchitis healing. Here, we report that the protein farnesylation/geranylgeranylation balance is critical for patients' fertility. The expression of geranylgeranyl diphosphate synthase 1 (GGPPS) was decreased due to elevated promoter methylation in the testes of infertile patients with mumps infection history. When we deleted GGPPS in mouse Sertoli cells, these cells remained intact, whereas the adjacent spermatogonia significantly decreased after the fifth postnatal day. The proinflammatory MAPK and NF-KB signaling pathways were constitutively activated in GGPPS ${ }^{-/-}$Sertoli cells due to the enhanced farnesylation of H-Ras. GGPPS ${ }^{-/-}$Sertoli cells secreted an array of cytokines to stimulate spermatogonia apoptosis, and chemokines to induce macrophage invasion into the seminiferous tubules. Invaded macrophages further blocked spermatogonia development, resulting in a long-term effect through to adulthood. Notably, this defect could be rescued by GGPP administration in EMCV-challenged mice. Our results suggest a novel mechanism by which mumps infection during childhood results in adult sterility.

\section{CORRESPONDENCE \\ Xiang Gao: \\ gaoxiang@nju.edu.cn \\ OR \\ Chao-Jun Li: \\ licj@nju.edu.cn}

Abbreviations used: BTB, blood-testis barrier; EMCV, encephalomyocarditis virus; FPP, farnesyl diphosphate;

FTase, farnesyl transferase; GGPP, geranylgeranyl diphosphate; GGPPS, geranylgeranyl diphosphate synthase 1; GGTase-I, geranylgeranyltransferase I.
Although the testes of mumps virus-infected patients exhibit degenerated seminiferous epithelia (Boström, 1968), the reason for spermatogenesis disruption remains a controversial and topical issue. For example, the evidence that has been obtained regarding the effects of the endocrine system in mediating mumps-related orchitis is conflicting. Although the observed defect in spermatogenesis may be the consequence of a drop in testosterone secretion by Leydig cells, testosterone and gonadotropin FSH and LH levels of adult patients were demonstrated to be decreased, increased, or even to remain normal and only transient changes as a result of mumps orchitis (Werner, 1950; Adamopoulos et al., 1978; Bertschat and Alexander, 1981).

In addition to Leydig cells, the mumps virus also infects other testis cells, such as Sertoli cells. These cells may ultimately survive from orchitis but exhibit a significant spermatogonia loss, i.e., Sertoli cell-only syndrome. In addition to

0 2013 Wang et al. This article is distributed under the terms of an AttributionNoncommercial-Share Alike-No Mirror Sites license for the first six months after Noncommercial-Share Alike-No Mirror Sites license for the first six months after
the publication date (see http://www.rupress.org/terms). After six months it is available under a Creative Commons License (Attribution-NoncommercialShare Alike 3.0 Unported license, as described at http://creativecommons.org/ licenses/by-nc-sa/3.0/) 
nurturing the developing spermatogonia, Sertoli cells are also at the center of the regulation of immune privilege during adulthood (Griswold, 1998; Fijak and Meinhardt, 2006). A physical barrier, the so-called blood-testis barrier (BTB), forms between Sertoli cells and allows for these cells to control and regulate the environment of the developing germ cells. More importantly, in addition to the BTB, Sertoli cells can secrete immunomodulatory factors that create an effectively immuneprivileged environment (Luster, 1998; Guazzone et al., 2009). This property of Sertoli cells has been widely used for various allograft and xenograft transplantation studies (Fallarino et al., 2009; Mital et al., 2010). When islets were transplanted into diabetic mice, graft survival was significantly prolonged to at least $100 \mathrm{~d}$ when cotransplanted with Sertoli cells of xenogeneic mice and even rats compared with islets that were engrafted alone. This result was achieved without the requirement of immunosuppressant treatment compared with islets engrafted alone when cotransplanted with Sertoli cells of xenogenic mice, and even rat (Korbutt et al., 1997; Korbutt et al., 2000).

Intriguingly, the success of cotransplantation was dependent on the age of Sertoli cell mouse donor. Only Sertoli cells that were isolated from pubertal or adult testes, but not those from neonatal testes, could successfully protect the cotransplanted islets (Mital et al., 2010). These results suggest that the properties of immature Sertoli cells differ from those of pubertal or adult Sertoli cells. This fact raises the question of how testes maintain the immune balance during the neonatal stage and protect the spermatogonia from immune attack when the testes experience traumatic insults or bacterial and viral infections before puberty. Another paradoxical issue with respect to mumps susceptibility in human children is that testosterone levels are low and there is no gonadotropin secretion during this stage of development. Moreover, the BTB does not form between Sertoli cells until puberty (Fijak and Meinhardt, 2006; Griswold, 1998). Thus, the understanding of the mechanism that underlies the immune response in the testis before puberty is a matter of clinical importance in the prevention of future infertility.

It has been reported that the protein prenylation level and the ratio of geranylgeranylated (modified with a GGPP moiety) to farnesylated (modified with a FPP moiety) proteins were higher in the premeiotic and meiotic stages of spermatogenesis before sexual maturity and decreased with age in rat (Dugan and Allen, 1995). FPP and GGPP prenylate proteins that have a CaaX motif in their carbon termini, such as the RAS superfamily of GTPases (Ashby, 1998). We compared the expression of GGPPS, a synthetase of GGPP from FPP, and observed that the GGPPS levels in the testes of infertile patients with a mumps infection history were significantly lower compared with noninfected infertile patients. Thus, we hypothesize that lower GGPPS expression may result in the altered prenylation of signaling molecules that affect the immune response in the testes of children. Thus, we generated different testicular cell-specific GGPPS knockout mice. We were excited to observe that GGPPSregulated protein prenylation in Sertoli cells (a) is crucial for spermatogonia survival during childhood, a stage at which there is no BTB or gonadotropin secretion, and (b) is thereby required for adult fertility. GGPPS-deleted Sertoli cells secrete proinflammatory cytokines and chemokines, which stimulate spermatogonia apoptosis and induce macrophage invasion into the seminiferous tubules. These effects lead to a long-term inhibition of spermatogonia development. Our data provide a novel model with which to examine orchitisrelated infertility resulting from childhood viral infections, such as mumps.

\section{RESULTS \\ GGPPS deletion in mouse Sertoli cells leads to altered protein prenylation during childhood}

We observed that GGPPS expression in the testis of infertile patients with a history of mumps infection was significantly lower compared with noninfected infertile patients (Fig. 1 A). Given that the virus normally uses a promoter methylation strategy to suppress antiviral gene expression in host cells (Mikovits et al., 1998; Kondo et al., 2000; Feng et al., 2010), we examined the methylation of the GGPPS promoter and determined that the methylation level was enhanced in infertile patients with a history of mumps infection (Fig. 1, B and C). Given that GGPPS was primarily observed in the cytoplasm of Sertoli cells and spermatogonia (Fig. 1 D), we deleted the GGPPS gene in Sertoli cells (Sc-GGPPS ${ }^{-/}$) by crossing GGPPS-LoxP-targeted allele (exons 3-4) mice with AMHCre transgenic mice (Lécureuil et al., 2002; Fig. 1, E and F). GGPPS was also deleted in spermatogonia (unpublished data). LC-MS detection indicated that the GGPP level was significantly decreased in GGPPS-deleted Sertoli cells (Fig. 1 G). The radiolabelled incorporation of GGPP in isolated Sertoli cells from third postnatal day testes indicated that total protein geranylgeranylation levels were significantly decreased by GGPPS deletion (Fig. $1 \mathrm{H}$ ). The membrane association (Fig. $1 \mathrm{I}$ ) and prenylation (Fig. $1 \mathrm{~J}$ ) of both RAC1 and Rab1, two $G$ proteins that can only be geranylgeranylated, were decreased. All of the biochemistry analyses suggested that GGPPS deletion, indeed, resulted in a block of protein geranylgeranylation and, consequently, a decrease in protein prenylation in Sertoli cells that were isolated from the testes of third postnatal day mice. The Sc-GGPPS ${ }^{-/-}$mice were born in the expected Mendelian ratios and had no observable abnormal phenotypes other than infertility (Fig. $1 \mathrm{~K}$ ).

Anatomical examinations indicated that the size (Fig. 2 A) and weight of both the testis and the epididymis of 8-wk-old Sc-GGPPS ${ }^{-1-}$ mice were significantly decreased (Fig. 2 B), and no body weight differences were observed (unpublished data). Furthermore, the epididymal sperm count indicated that there was only a few thousand sperm per milliliter (Fig. 2 C). The testes of 8-wk-old Sc-GGPPS ${ }^{-/-}$mice were severely defective. The total tubule number decreased, and the majority of the tubes were hollow without developing spermatocytes (Fig. 2, D and E). Surprisingly, although the GGPPS gene was deleted in Sertoli cells, but not in spermatogonia, the number of Sertoli cells in testicular tubules was unaltered, 

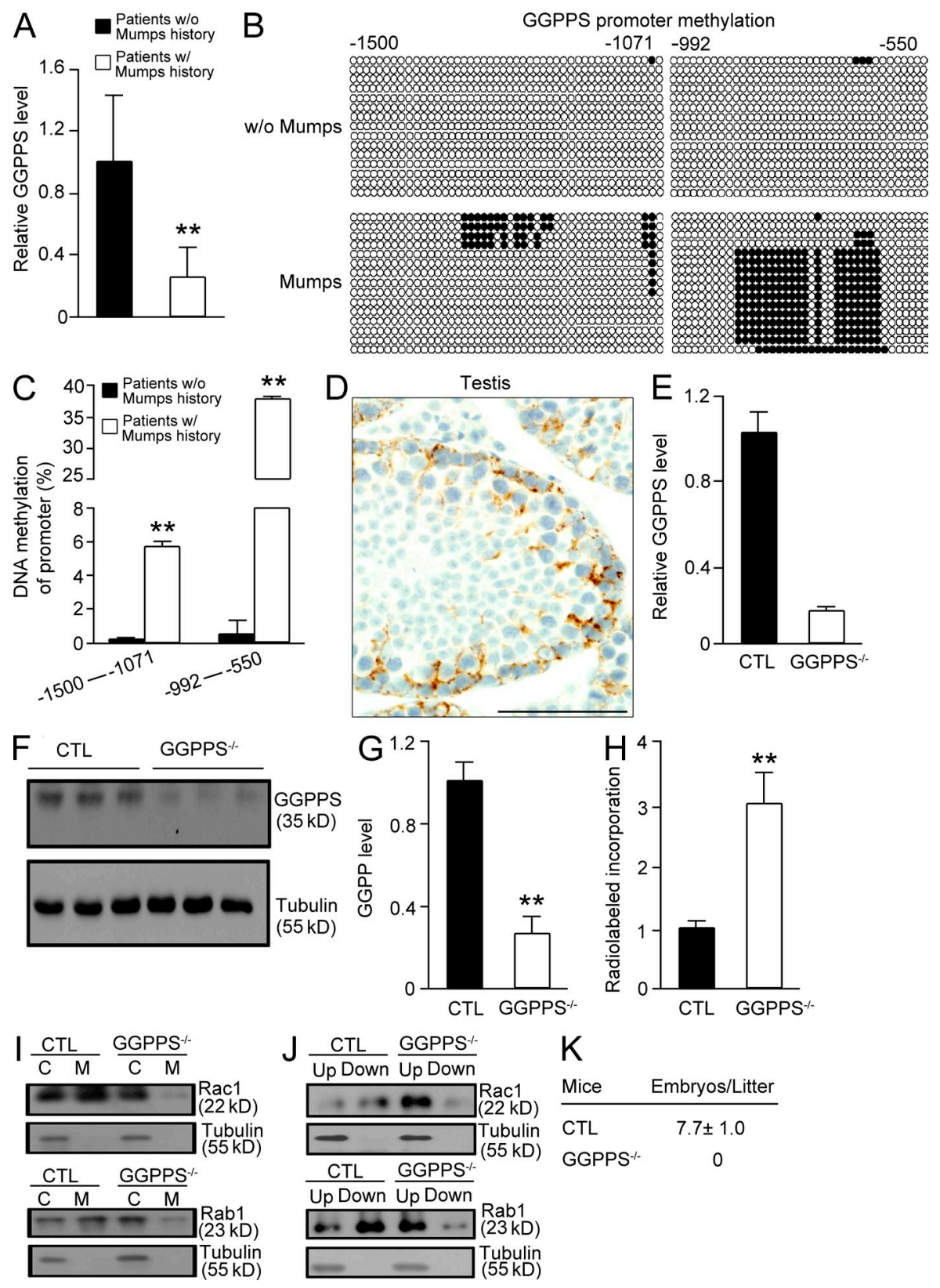

Figure 1. The GGPPS expression level decreased due to increased promoter methylation in mumps-infected infertile patients, and GGPPSdeleted Sertoli cells exhibited decreased geranylgeranylation levels in the testis of third postnatal day mice, leading to adulthood infertility. (A) GGPPS expression in the testis biopsy samples from infertile patients was analyzed using qRT-PCR. GGPPS transcript levels in infertile patients with a history of mumps $(n=9)$ versus subject with no history of infection $\left(n=7 ;{ }^{* *}, \mathrm{P}=0.0012\right)$. (B and $\left.\mathrm{C}\right)$ The methylation level of GGPPSs promoter in the testis tissue in infertile patients with a history of mumps $(n=9)$ versus no history $\left(n=7 i^{* *}, P=0.000685\right.$ [left] and ${ }^{* *}, P=0.000232$ [right]). (D) Immunostaining of the GGPPS protein in the cytosol of the Sertoli cells and the spermatogonia ( $n=5$ ). (E and F) qRT-PCR of GGPPS mRNA (E) and Western blotting of GGPPS protein (F) in isolated Sertoli cells from the testis of third postnatal day mice. (G) The GGPP level in Sertoli cells after GGPPS inactivation $\left({ }^{* *}, P=0.000106\right)$. (H) Radiolabeled GGPP incorporation in GGPPS-deleted Sertoli cells $\left({ }^{*}, P=0.0037\right)$. The membrane association $(I)$ and prenylation (J) of both Rac1 and Rab1 after GGPPS deletion in Sertoli cells. (K) Fertility analysis from deletion in Sertoli cells $(n=7)$. All of the groups of experimental animals contained a minimum of five mice. All of the data are representative of at least three replicates and are presented as the mean and the SEM. ${ }^{*}, \mathrm{P}<0.05$, versus control; ${ }^{*}, \mathrm{P}<0.005$, versus control. Bar, $100 \mu \mathrm{m}$.

whereas the number of spermatogonia was significantly decreased (Fig. 2, F and G). This result was supported by immunohistochemical staining with the Sertoli cell marker WT1 and the germ cell marker MVH, respectively (Fig. 2, H and I).
We then determined when the defect in the testis occurred, finding significant differences in testicular weight and degeneration in Sc-GGPPS ${ }^{-/-}$mice compared with their litter mate controls as early as the fifth postnatal 

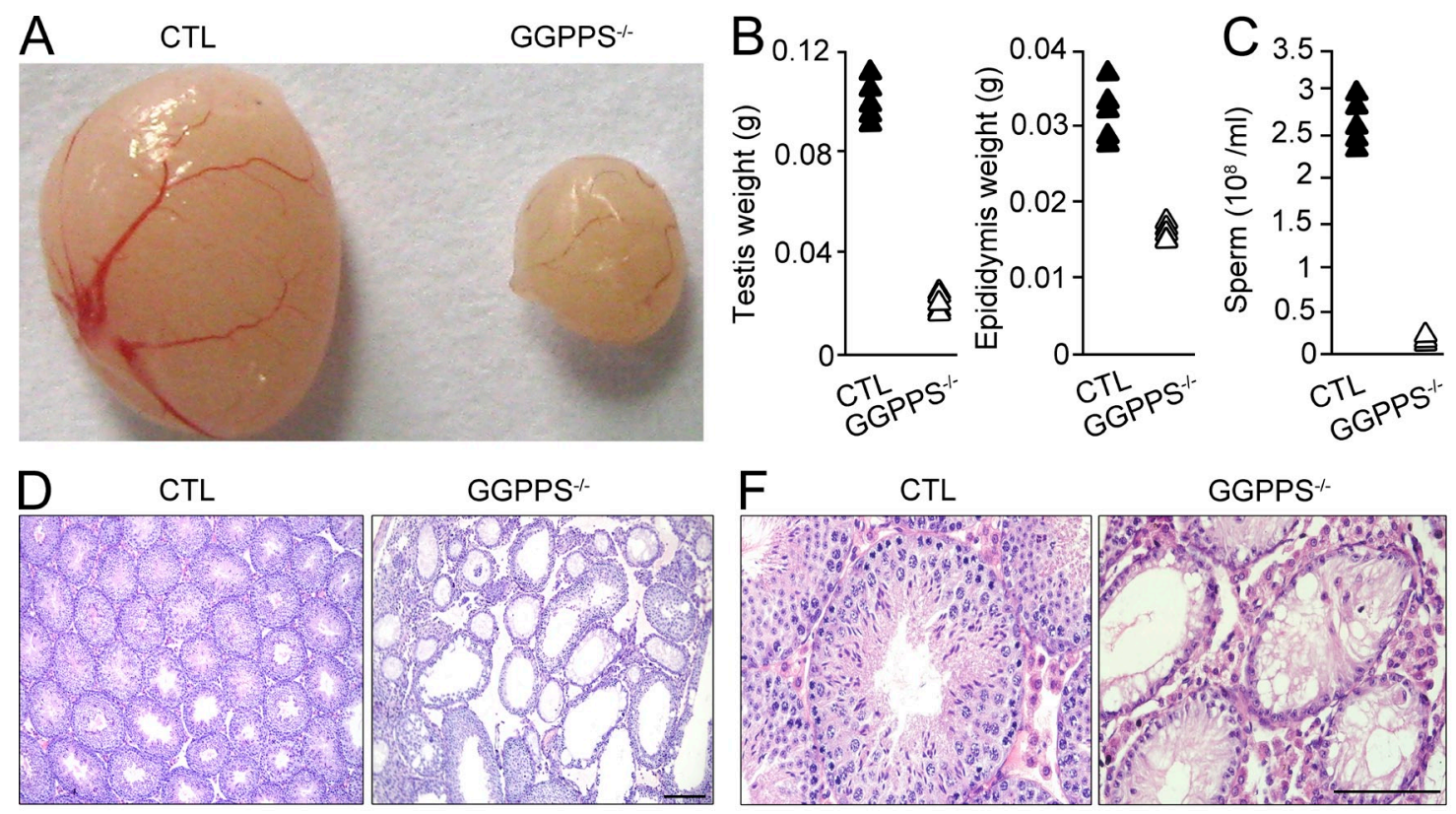

GGPPS ${ }^{-1-}$
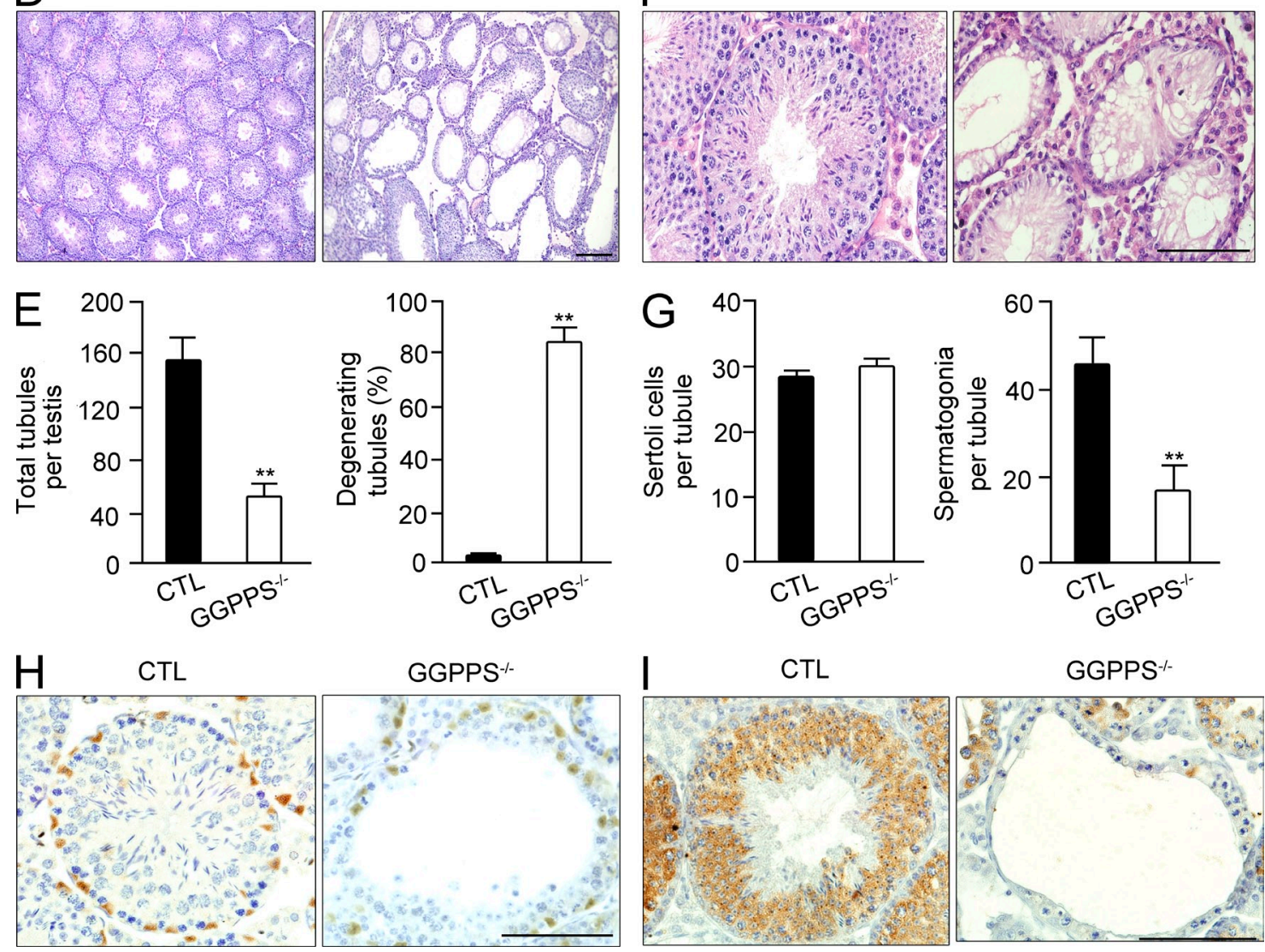

Figure 2. Altered protein prenylation caused by GGPPS deletion in Sertoli cells leads to spermatogonia loss, but no Sertoli cell defect. (A and B) Gross analysis of testes and epididymises for control and Sc-GGPPS-1- mice. (C) Sperm count in the epididymis. (D) H\&E staining of testis in 8-wk-old Sc-GGPPS ${ }^{-1-}$ and control mice. (E) Total tubules number $\left.{ }^{* *}, \mathrm{P}=1.09 \mathrm{E}-05\right)$ and the number of degenerated tubules $\left(^{* *}, \mathrm{P}=3.66 \mathrm{E}-09\right)$. (F and $\left.\mathrm{G}\right) \mathrm{H} \& \mathrm{E}$ staining of testis and cell counting in 8-wk-old Sc-GGPPS ${ }^{-1-}$ and control mice $\left({ }^{*}, \mathrm{P}=5.03 \mathrm{E}-05\right)$. (H and I) The immunohistochemical analyses with antibodies against the Sertoli cell marker WT1 (H) and the spermatogonium marker MVH (I). WT1-positive Sertoli cell and MVH-positive germ cells numbers in 8-wk-old Sc-GGPPS ${ }^{-1-}$ versus control mice. All of the groups of experimental animals contained a minimum of five mice. A minimum of 10 fields per slide and a minimum of five slides were counted for the cell number analysis. All of the data are representative of at least three replicates and are presented as the mean and SEM. ${ }^{* *}, \mathrm{P}<0.005$, versus control. Bar, $100 \mu \mathrm{m}$.

(Fig. 3, A-C). WT1 (Fig. 3 D) and MVH (Fig. 3 E) staining confirmed that the spermatogonia number but not the Sertoli cell number dramatically decreased after the fifth postnatal day. This result suggests that GGPPS deletion in Sertoli cells leads to adult infertility caused by spermatogonia loss, but not a Sertoli cell defect, as early as the fifth postnatal day.
Inactivation of GGPPS in Sertoli cells results in cytokine and chemokine release, inducing spermatogonia apoptosis and seminiferous tubule macrophage invasion

Unexpectedly, although GGPPS was knocked out in Sertoli cells, these cells appeared intact, and rather it was the number of spermatogonia that decreased from the fifth postnatal day. We hypothesize that GGPPS deletion induces Sertoli cells to 

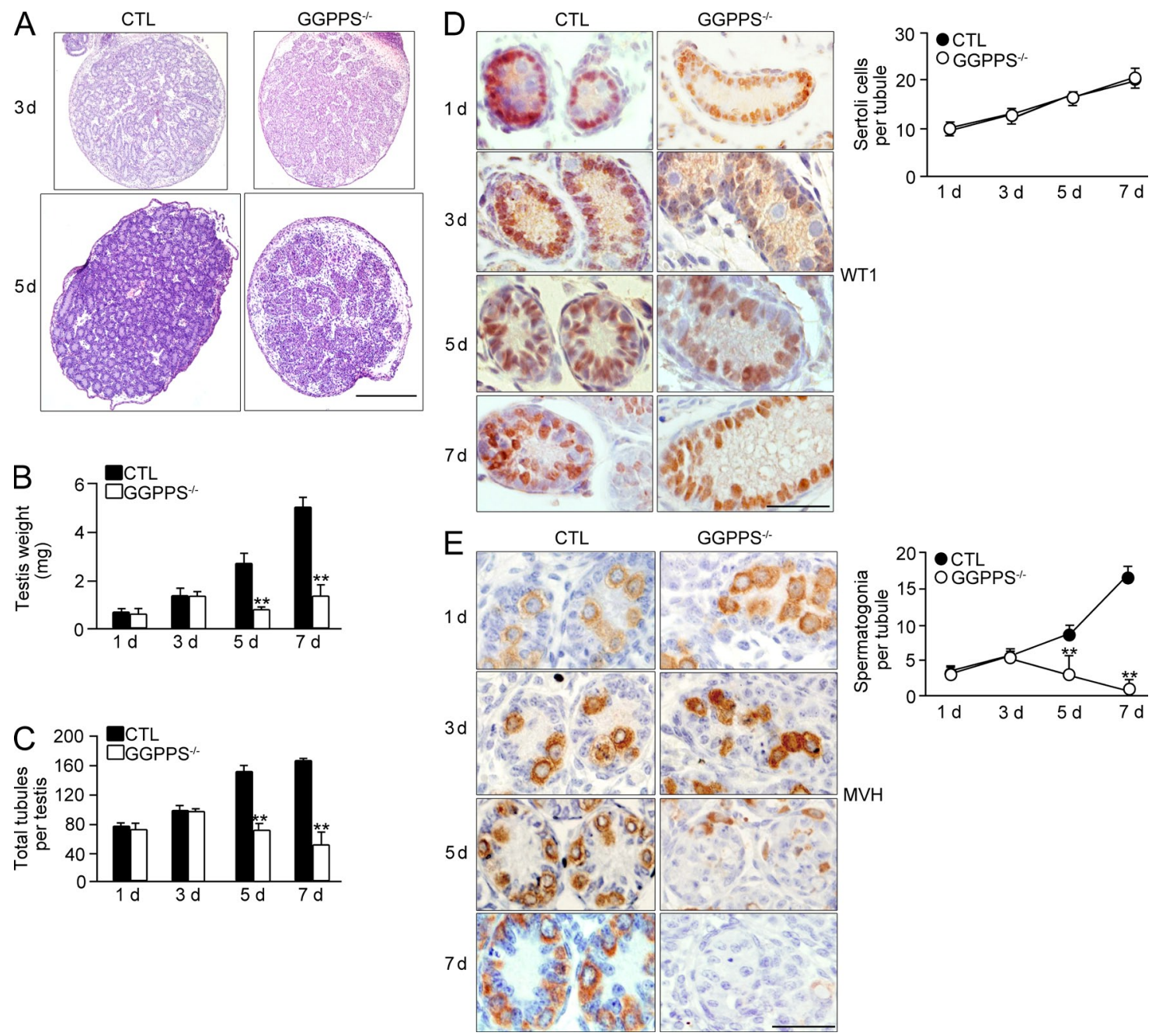

Figure 3. Spermatogonia loss occurred as early as fifth postnatal day. (A) H\&E staining of the testes from third to fifth postnatal day mice. ( $B$ and $C$ ) Testis weight $\left(5 d_{1}{ }^{* *}, P=0.00137 ; 7 d_{1}{ }^{* *}, P=2.59 E-07\right)$ and total testicular tubule number $\left(5 d^{*}{ }^{* *}, P=6.84 E-06 ; 7 d^{*}{ }^{* *}, P=2.83 E-07\right)$ at indicated time points. ( $D$ and $E$ ) Immunohistochemical analyses of Sertoli cells and spermatogonia at indicated time points (spermatogonia, $5 \mathrm{~d},{ }^{* *}, P=0.00039$; $\left.7 d_{1}{ }^{*}, P=6.89 E-07\right)$. All of the groups of experimental animals contained a minimum of five mice. A minimum of 10 fields per slide and a minimum of 5 slides were analyzed for cell number. All of the data are representative of at least three replicates and are presented as the mean and SEM. ${ }^{* *}$, $P<0.005$, versus control. Bars: $400 \mu \mathrm{m}(\mathrm{A}) ; 50 \mu \mathrm{m}$ (D and $\mathrm{E})$.

release effectors that can affect spermatogonium survival. This hypothesis was made given that the conditioned medium collected from the culture of GGPPS ${ }^{-/-}$Sertoli cells that were isolated at third postnatal day dramatically decreased the activity of cultured spermatogonia (Fig. 4 A). We therefore extracted mRNA from separated Sertoli cells of third postnatal day mice and used a cDNA microarray to analyze gene expression patterns after GGPPS deletion. This microarray analysis revealed that 1,623 distinct transcripts related to different biological processes were significantly differentially expressed between Sc-GGPPS ${ }^{-1-}$ and control mice (Fig. 4 B). Remarkably, there was a significant increase in a group of cytokine and chemokine genes among 239 immune-related genes (Fig. 4 C). Among these chemokines, CXCL5 increased in expression 80-fold, and the cytokine IL-6 increased in expression sevenfold. To test the significance of the expression profile data, we selected 10 genes for independent assays to measure their expression levels using qPCR. The selected genes were $I L-1 \alpha, I L-1 \beta, I L-6, C C L 2, C C L 3, C X C L 2$, CXCL3, CXCL5, TNF, and FasL and included genes that were significantly increased in expression based on the microarray data or have been reported to be critical for spermatogonia cell death (i.e., Fas $L$ and TNF). The change in expression of nearly all of the selected genes was reproducible with qPCR, and FasL expression was found to be unaltered in both the microarray and the qPCR data (Fig. 4 D). The qPCR analysis indicated that TNF expression significantly increased by 2.5fold, although an increase of only 1.7-fold was observed in the microarray assay (Fig. 4 D). The secretion of cytokines and chemokines from cultured Sertoli cells was also examined using a CytoArray assay. The result indicated a similar trend of increased expression as was found with the microarray data 


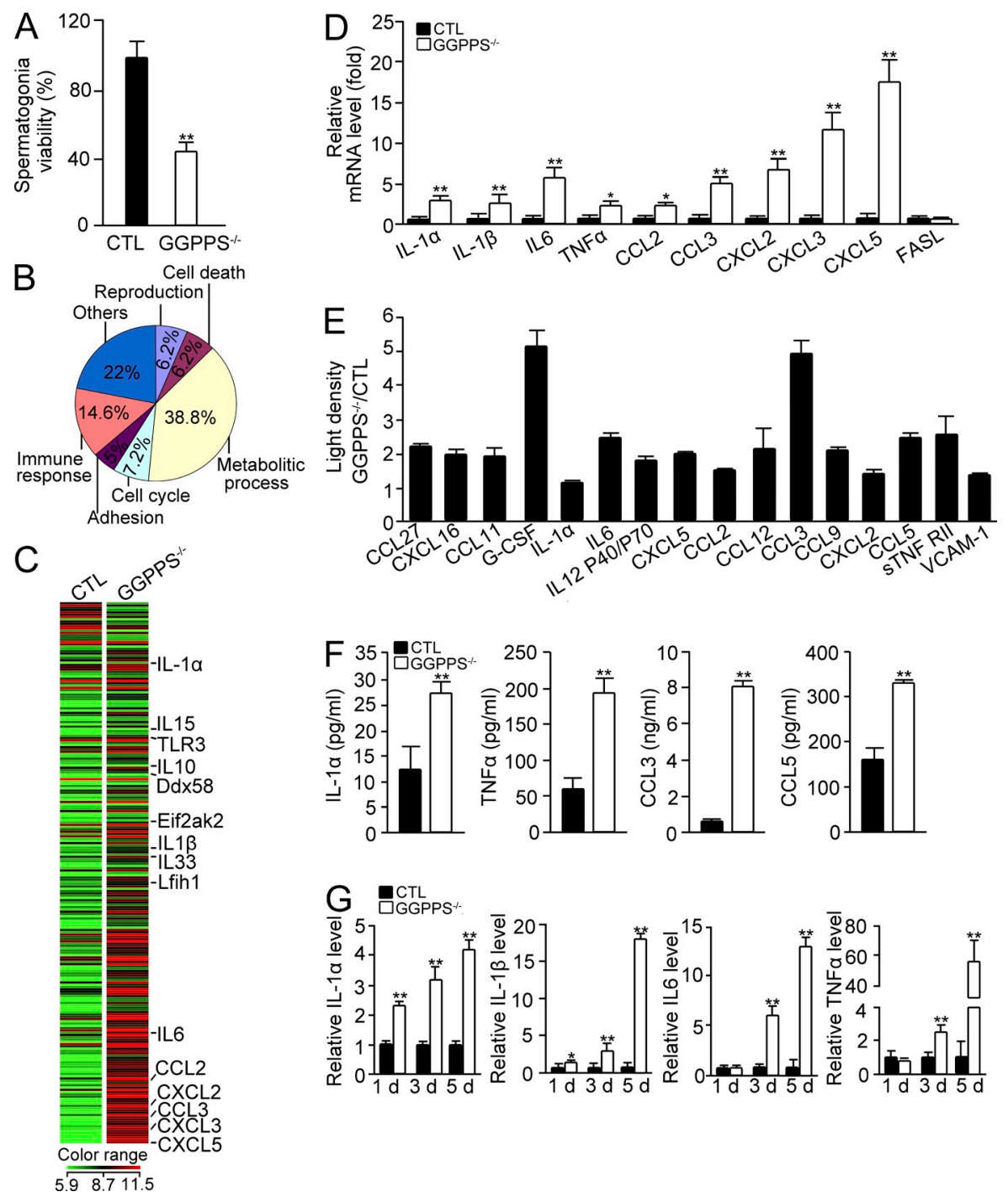

Figure 4. GGPPS inactivation in Sertoli cells results in cytokine and chemokine release. (A) Conditioned medium from isolated GGPPS ${ }^{-1-}$ Sertoli cells of third postnatal day testes was added to spermatogonia for viability after $24 \mathrm{~h}\left({ }^{*}, \mathrm{P}=0.000428\right)$. (B) The gene expression profiles of primary GGPPS $^{-1-}$ Sertoli cells from third postnatal day testes. For each group, the RNA came from 30 mice. The expression of 1,623 distinct transcripts was changed between the groups. (C) The heat map of the gene expression of 239 cytokine and chemokine genes of Sc-GGPPS ${ }^{-1-}$ and control mice. (D) qRT-PCR confirmation of selected genes from the gene expression profile in Sertoli cells from mice the third postnatal day $\left(I L-1 \alpha_{1}{ }^{* *}, P=0.000664 ; I L-1 \beta\right.$, ${ }^{*}, \mathrm{P}=0.000203 ; \mathrm{IL}-6,{ }^{* *}, \mathrm{P}=0.000203 ; T_{N F}{ }^{*}, \mathrm{P}=0.0446 ; C C L 2,{ }^{*}, \mathrm{P}=0.012 ; C C L 3,{ }^{* *}, \mathrm{P}=4.64 \mathrm{E}-06, \mathrm{CXCL2},{ }^{* *}, \mathrm{P}=0.000837 ; C X C L 3,{ }^{* *}, \mathrm{P}=3.66 \mathrm{E}-07$; $C X C L 5,{ }^{* *}, P=0.000852$ ). (E) The secretion of cytokines and chemokines from GGPPS-l- Sertoli cells from third postnatal day testes was analyzed using CytoArrays. (F) The secretion of cytokines and chemokines from GGPPS ${ }^{-1}$ - Sertoli cells of third postnatal day testes was analyzed using ELISAs (IL-1 $\alpha$, $\left.{ }^{* *}, \mathrm{P}=0.002543 ; \mathrm{TNF}^{*}{ }^{*}, \mathrm{P}=0.000744 ; \mathrm{CCL},{ }^{* *}, \mathrm{P}=3.4 \mathrm{E}-05 ; \mathrm{CCL} 5,{ }^{* *}, \mathrm{P}=0.000402\right)$. (G) The expression of IL-1 $\alpha, I L-1 \beta, I L 6$, TNF, and FasL in Sertoli cells at different postnatal days $\left(I L-1 \alpha, 1 d_{1}{ }^{* *}, P=0.000885 ; 3 d_{1}{ }^{* *}, P=8.37 E-06 ; 5 d_{1}{ }^{* *}, P=0.00065 ; I L-1 \beta, 1 d_{1}{ }^{*}, P=0.033 ; 3 d_{1}{ }^{* *}, P=0.00325 ; 5 d_{1}{ }^{* *}, P=\right.$ 4.97E-06; $\left.I L-6,3 d{ }^{* *}, P=2.91 E-05 ; 5 d,{ }^{* *}, P=5.15 E-05 ; T N F, 3 d,{ }^{* *}, P=0.001581,5 d,{ }^{* *}, P=0.001273\right)$. All of the groups of experimental animals contained a minimum of five mice. All of the data are representative of at least three replicates and are presented as the mean and $\mathrm{SEM}$. ${ }^{*}, \mathrm{P}<0.05$, versus control; **, $\mathrm{P}<0.005$, versus control.

(Fig. 4 E). This result was further quantitatively confirmed with ELISA. We observed that, after GGPPS deletion in Sertoli cells, the IL- $1 \alpha$ level increased by 2.2 -fold to $27 \mathrm{pg}$; the TNF level increased by 3.2-fold to $194 \mathrm{pg}$; the CCL3 level increased by 11 -fold to $8 \mathrm{ng}$; and the CCL5 level increased by 2 -fold to $330 \mathrm{pg}$ (Fig. $4 \mathrm{~F}$ ). We also ascertained the time course of the expression of selected cytokine and chemokine genes in Sertoli cells from mice of different postnatal days. We observed that the expression of $I L-1 \alpha$ and $I L-1 \beta$, which are two proinflammatory cytokines, were increased as early as the first day after birth in the GGPPS-deleted Sertoli cells. In contrast, the increased expression of other cytokines, such as $I L-6$ and TNF, was delayed to the third postnatal day (Fig. 4 G). 
GGPPS is a branch-point enzyme in the mevalonate metabolic pathway and catalyzes the synthesis of GGPP that is used to geranylgeranylate protein with CaaX motif. To determine whether protein geranylgeranylation, indeed, involved the cytokine and chemokine secretion by Sertoli cells, we administered GGPP or the GGTase-I inhibitor GGTI to Sertoli cells from Sc-GGPPS ${ }^{-1-}$ mice or wild-type mice, respectively. We observed that GGPP administration largely inhibited the gene expression of cytokines and chemokines from Sc-GGPPS ${ }^{-/-}$Sertoli cells in a dose-dependent manner (Fig. 5 A). In contrast, GGTI administration significantly increased the gene expression of cytokines and chemokines in wild-type Sertoli cells in a dose-dependent manner (Fig. 5 B). This result suggests that protein geranylgeranylation is essential for Sertoli cells to synthesize cytokines and chemokines. The increase in IL- 6 and TNF expression can result in their binding to their respective receptors on spermatogonia, inducing apoptosis (Theas et al., 2003; Guazzone et al., 2009; Yao et al., 2009). The number of apoptotic cells in the tubules of Sc-GGPPS ${ }^{-1-}$ mice was therefore observed to be increased between the third and the fifth postnatal days, and then decreased at the seventh postnatal day (Fig. 5 C). We also observed that the expression of G-CSF and chemokines, such as CCL2 (MCP-1), CCL3 (MIP-1 $\alpha$ ), CXCL2 (MIP-2 $\alpha$ ), was increased after GGPPS deletion in Sertoli cells. These chemokines can recruit macrophages and stimulate the proliferation of tissueresident macrophage, augmenting the inflammation response (Chen et al., 1988; Fahey et al., 1992; Gordon and Taylor, 2005; Mantovani et al., 2004; Neels and Olefsky, 2006). The immunofluorescence analysis of F4/80 in testis sections indicated few tissue-resident macrophages in the testis interstitium of wild-type mice. In contrast, GGPPS deletion stimulated macrophage proliferation. These cells invaded the lumen of seminiferous tubules in Sc-GGPPS ${ }^{-/-}$mice testis at the fifth and seventh postnatal day (Fig. 5 D). As there is no BTB between Sertoli cells at this age in mice, the proliferated macrophages were able to easily invade the lumen of the seminiferous tubules and to survive as long as $\sim 4$ wk (Fig. 5 D). Invaded macrophages destroy differentiated spermatogonia in the future, given that the latter are foreign to the mature immune system. We observed that there was second wave of apoptosis near the 14th postnatal day in addition to the first wave that occurred between the third and fifth postnatal day (Fig. 5 C). Therefore, even if spermatogonia escaped from the cytokine attack during the early postnatal stage, resident macrophages in the lumen could further block spermatogonium development after puberty in Sc-GGPPS ${ }^{-/-}$mice, resulting in a long-term effect on adult fertility. This observation can explain why a mumps infection during childhood may occasionally lead to adult infertility.

\section{MAPK Erk1/2 and NF-кB are constitutively activated by GGPPS deletion in Sertoli cells, inducing spermatogonial loss, testis defects, and adult infertility}

Sertoli cells play a critical role during the innate immune response against viral infection though TLR signaling (Riccioli et al., 2006; Starace et al., 2008; Sun et al., 2010). Sertoli cells can recognize RNA viruses (e.g., the mumps virus) through cytosolic sensors, including EIF2AK2, DDX58, and IFIH1 (Clemens et al., 1993; Luster, 1998; Andrejeva et al., 2004; Yoneyama et al., 2004). The gene expression of these sensors increased 2.4-, 3.0-, 6.5-, and 3.6-fold in GGPPS ${ }^{-1-}$ Sertoli cells (Gene Expression Omnibus database accession no. GSE35755). This result suggests that GGPPS inactivation induces the cell to behave as if virally infected.Viral infection and other insults lead to the activation of proinflammatory signals, NF- $\mathrm{B}$, and mitogenactivated protein kinase (MAPK; Kawai and Akira, 2006), which were found to be constitutively activated in Sertoli cells after GGPPS deletion (Fig. 6, A-C). NF-кB activation was determined to be dependent on Erk1/2 activation given that U0126 blocked NF- $\mathrm{B}$ activation in GGPPS-deleted Sertoli cells (Fig. 6, $\mathrm{D}$ and $\mathrm{E})$. When the NF- $\mathrm{KB}$ inhibitor bortezomib was intraperitoneally administered to Sc-GGPPS ${ }^{-1-}$ mice on the first postnatal day, the defective testis weight phenotype was rescued (Fig. 6 F). H\&E and MVH staining (Fig. 6 G) also indicated that the seminiferous tubule degeneration (Fig. $6 \mathrm{H}$ ) and the spermatogonial defect (Fig. 6 I) were partially rescued. Mating experiments indicated that $\mathrm{Sc}-G G P P S^{-/-}$mice were ultimately able to recover their fertility; two of five Sc-GGPPS ${ }^{-/-}$mice impregnated females after bortezomib administration (Fig. $6 \mathrm{~J}$ ).

\section{GGPPS deletion results in increased H-Ras farnesylation in Sertoli cells, leading to a spontaneous hyperinflammatory response in the testes}

We previously reported that GGPPS regulated Erk1/2 activation by altering Ras prenylation (Yu et al., 2011), which can be modified with both GGPP and/or FPP depending on the properties of the CaaX motif in the carboxyl terminus of the given protein (Ashby, 1998; Scott Reid et al., 2004). Previous studies have indicated that the mevalonate metabolic pathway inhibitor statin could act as an antiinflammatory drug by inhibiting both protein farnesylation and geranylgeranylation (Greenwood et al., 2006; Paraskevas, 2008). However, both our study, in which GGPPS was inactivated in Sertoli cells, and another study, in which GGTase-I was inactivated in macrophages (Khan et al., 2011), revealed that blocking geranylgeranylation enhanced the inflammatory response. We observed that the membrane association (Fig. $7 \mathrm{~A}$ ) and prenylation of pan-Ras (Fig. 7 B) were both increased after GGPPS deletion in Sertoli cells. Detailed analyses indicated that, among Ras superfamily proteins, the membrane association (Fig. 7 A) and prenylation (Fig. 7 B) of H-Ras were enhanced by GGPPS deletion in a protein farnesylation-dependent manner (Fig. 7 C), suggesting that increased farnesylation of H-Ras may be responsible for MAPK and NF-kB activation. When we transfected GGPPS-deleted Sertoli cells with a mutated form of H-Ras (H-Ras-186S) in which the farnesylation site was mutated and could not be farnesylated, both Erk1/2 and NF-кB activation (Fig. $7 \mathrm{D}$ ) and $I L-1 \alpha$ and $I L-1 \beta$ expression (Fig. $7 \mathrm{E}$ ) were blocked. This result suggests that, although protein geranylgeranylation was largely blocked by GGPPS deletion, Ras prenylation is enhanced because the increase in farnesylation can compensate for the decrease in geranylgeranylation to 

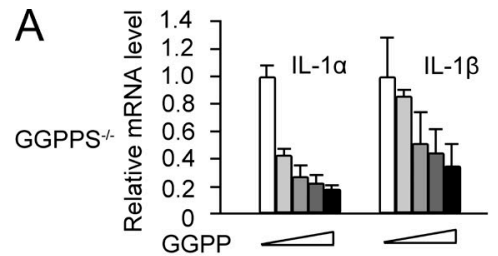

B
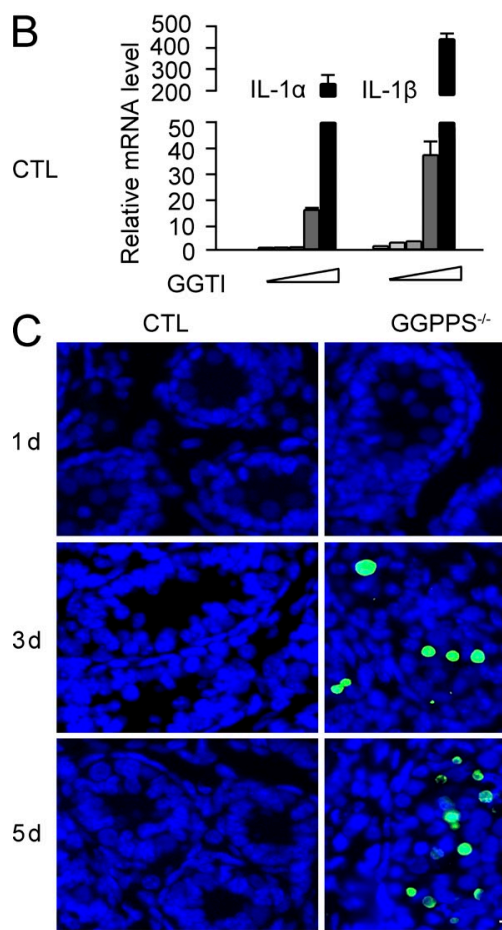

D
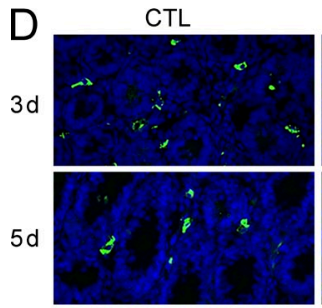

$7 d$

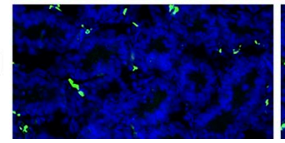

GGPPS ${ }^{-1-}$

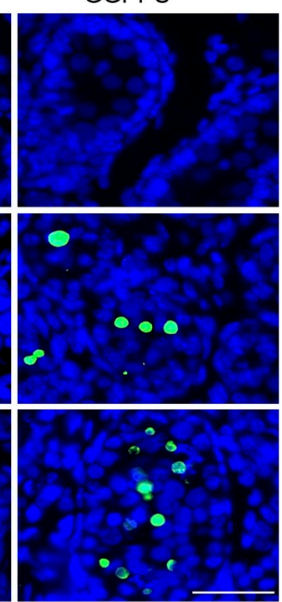

GGPPS $^{-1-}$

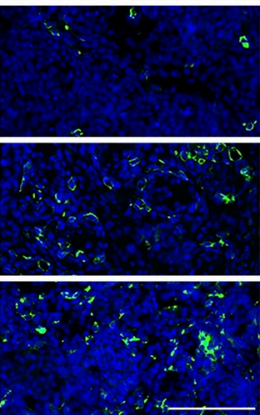

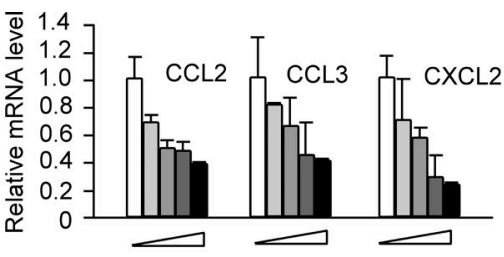
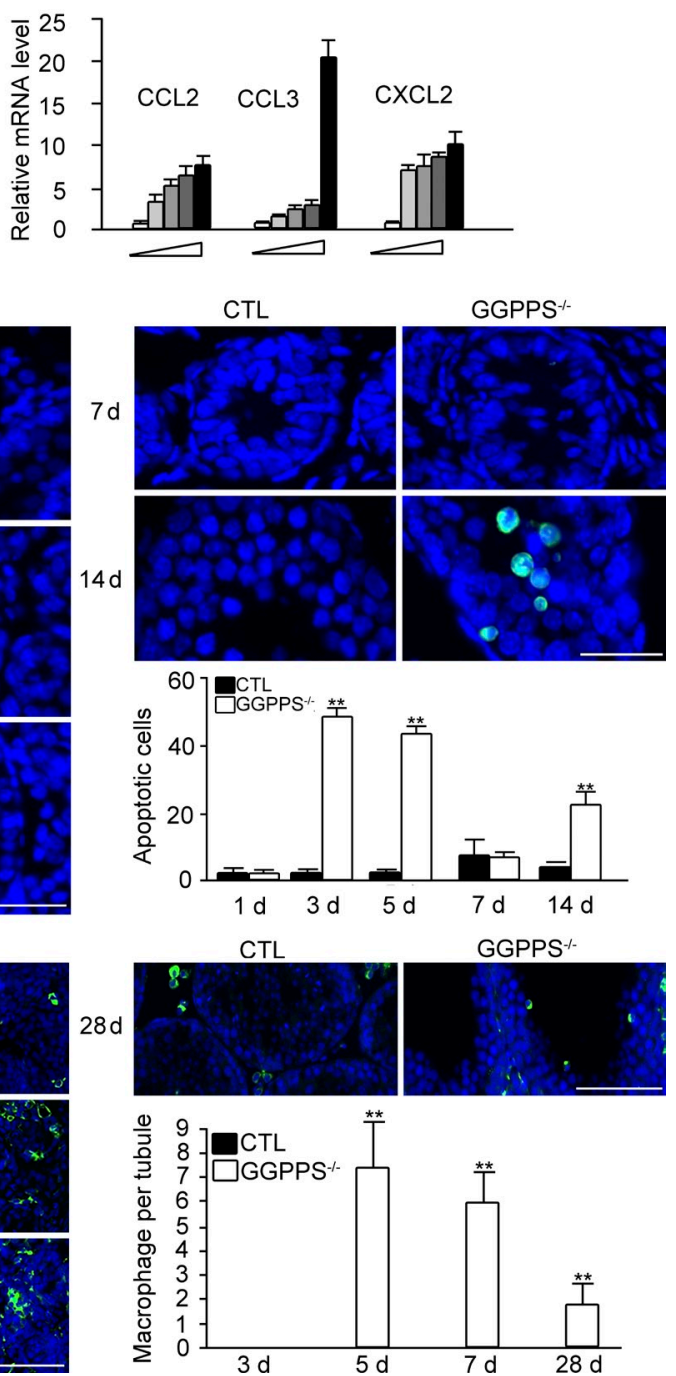

Figure 5. Proinflammation cytokines and chemokines may be related to spermatogonia apoptosis and seminiferous tubule macrophage invasion, both of which result in a long-term effect on adult fertility. ( $A$ and $B$ ) Expression level of cytokines after treatment with increasing doses of $\operatorname{GGPP}(4,8,16,32 \mu \mathrm{M} ; 24 \mathrm{~h})$ in $\operatorname{GGPPS}^{-1-}$ Sertoli cells (A), and by GGTI treatment $(1,2,4$, and $8 \mu \mathrm{M} ; 48 \mathrm{~h})$ in wild-type Sertoli cells from third postnatal day testes (B). (C) Apoptosis in the testis was assayed using TUNEL. The green dots represent apoptotic cells, and DAPI (blue) indicates cell nuclei $\left(3 d^{*}{ }^{*}, P=2.4 E-11 ; 5 d^{* *}, P=1.02 E-08 ; 14 d^{*}{ }^{*}, P=1.55 E-07\right)$. (D) The macrophages that invaded into the tubules were examined with the macrophage marker $\mathrm{F} 4 / 80$ in the testis sections $\left(5 d_{1}{ }^{* *}, P=2.6 E-08 ; 7 d_{1}{ }^{*}, P=1.75 E-09 ; 28 d^{*}{ }^{*}, P=0.000422\right)$. All of the groups of experimental animals contained a minimum of five mice. A minimum of 10 fields per slide and a minimum of 5 slides were counted for the cell number analyses. All of the data are representative of at least three replicates and are presented as the mean and SEM. ${ }^{*}, \mathrm{P}<0.05$, versus control; ${ }^{* *}, \mathrm{P}<0.005$. Bar, $100 \mu \mathrm{m}$.

transduce the proinflammatory signal to NF- $\mathrm{kB}$. Why does GGPPS deletion in Sertoli cells result in an increase in $\mathrm{R}$ as farnesylation? As the substrate of GGPPS in the synthesis of GGPP, FPP may accumulate in GGPPS-deleted Sertoli cells. LC-MS detection indicated that the FPP levels were, indeed, significantly increased in GGPPS-deleted Sertoli cells (Fig. 7 F).
The analysis of radiolabeled FPP incorporation also suggested that total protein farnesylation was enhanced (Fig. 7 G). Thus, H-Ras prenylation was enhanced because of FPP accumulation, (Fig. $7 \mathrm{H}$ ). The prenylation of N-Ras and K-Ras remained unchanged or slightly decreased (Fig. $7 \mathrm{H}$ ), whereas Rap1a, Rac1, and Rabs prenylation was decreased (Fig. 7 I). 

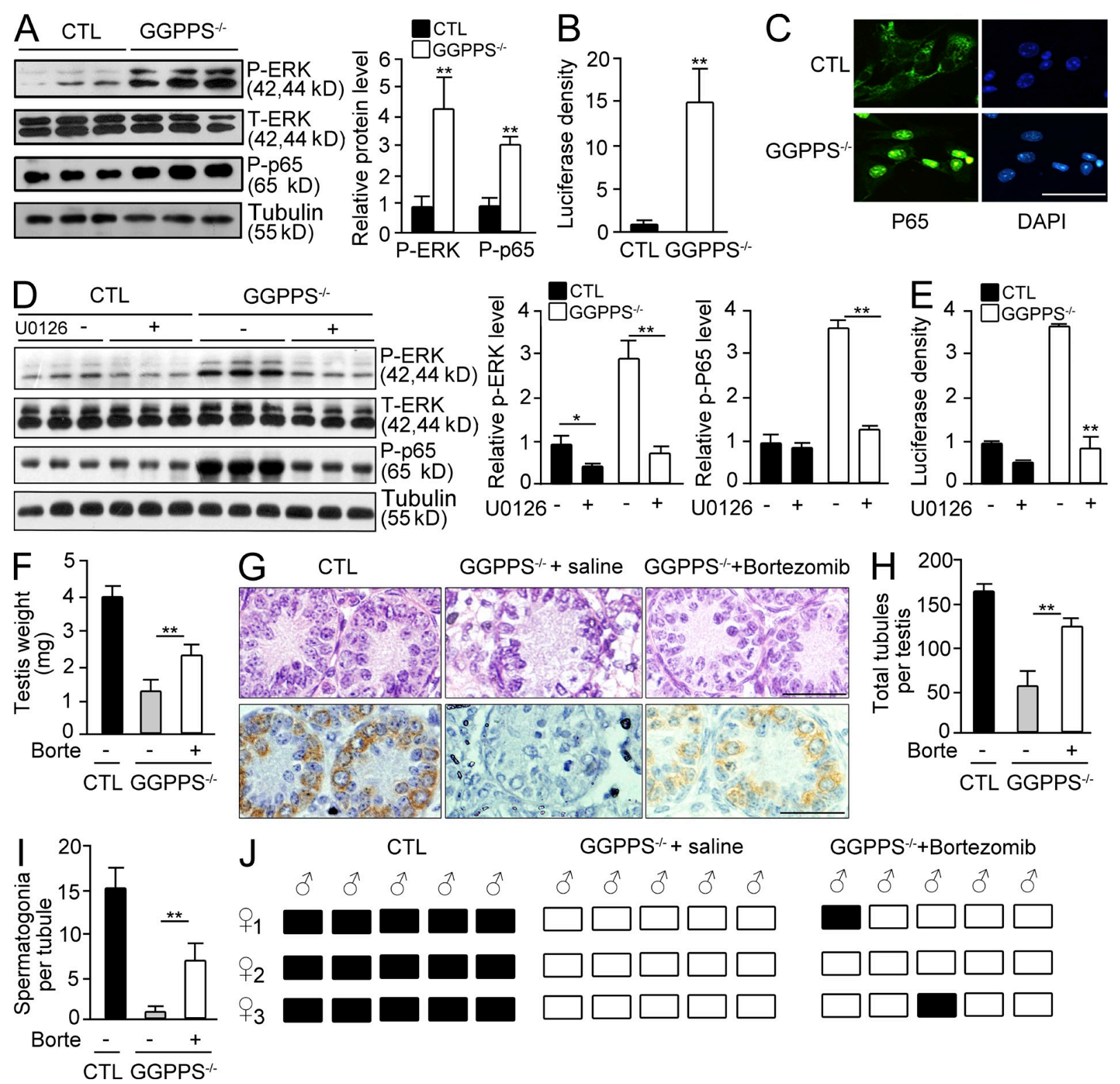

Figure 6. MAPK Erk1/2 and NF-кB are constitutively activated by GGPPS deletion in Sertoli cells and are responsible for the spermatogonial cell loss and testis defects. (A) Erk1/2 and NF- $\kappa B$ activating in GGPPS ${ }^{-1-}$ Sertoli cells (P-ERK, $\left.{ }^{* *}, P=0.00468 ; P-p 65,{ }^{* *}, P=0.000145\right)$. (B and C) $N F-\kappa B$ activation was examined by using a NF- $\kappa B$ luciferase reporter gene assay $\left({ }^{*}, P=0.00426\right)$ and immunostaining of p65. (C) $P 65$ distribution in the nucleus of GGPPS ${ }^{-1-}$ Sertoli cells. (D and E) The relationship between Erk1/2 and NF-кB activation was analyzed using Western blotting (ERK, CTL DMSO versus CTL U0126, ${ }^{*}, P=0.013 ; \mathrm{KO}$ DMSO versus $\mathrm{KO}$ U0126, ${ }^{*}, \mathrm{P}=0.000251 ; \mathrm{P} 65, \mathrm{KO}$ DMSO versus $\mathrm{KO}$ U0126, $\left.{ }^{* *}, \mathrm{P}=1.69 \mathrm{E}-05\right)$ and a NF- $\mathrm{kB}$ reporter gene assay after $\mathrm{U} 0126$ pretreated (D). NF- $\kappa B$ promoter-driven luciferase activity after U0126 treatment $\left({ }^{*}, \mathrm{P}=0.000105\right.$; E). (F) Testis size after intraperitoneal administration of bortezomib into Sc-GGPPS ${ }^{-1-}$ mice of first postnatal day $\left.{ }^{* *}, \mathrm{P}=0.00142\right)$. $(\mathrm{G}-\mathrm{I}) \mathrm{H} \& \mathrm{E}$ and MVH staining of testis at seventh postnatal day $(\mathrm{G})$. Seminiferous tubule $\left({ }^{* *}, \mathrm{P}=0.00104 ; \mathrm{H}\right)$ and spermatogonial $\left({ }^{* *}, \mathrm{P}=8.88 \mathrm{E}-05 ; \mathrm{I}\right)$ after bortezomib treatment. (J) Pregnancy analysis of Sc-GGPPS ${ }^{-1-}$ mice after bortezomib administration upon reaching adulthood. All of the groups of experimental animals contained a minimum of five mice. A minimum of 10 fields per slide and a minimum of five slides were counted for the cell number analyzes. All of the data are representative of at least three replicates and are presented as the mean and SEM. ${ }^{*}, \mathrm{P}<0.05$, versus control; ${ }^{*}, \mathrm{P}<0.005$, versus control. Bar, $50 \mu \mathrm{m}$.

This observation suggested that the increase in protein farnesylation in Sertoli cells is responsible for the MAPK and NF- $\mathrm{kB}$ activation, and thus for the augmentation of cytokine and chemokine levels. Thus, we used FTI to inhibit protein farnesylation in GGPPS-deleted Sertoli cells and observed that the activation of Erk1/2 and NF-KB was blocked (Fig. 8, A and B).
FTI administration also blocked the production of IL-1 $\alpha$ and IL-1 $\beta$ in knockout Sertoli cells (Fig. 8 C). The intraperitoneal administration of FTI into first postnatal day Sc-GGPPS ${ }^{-1-}$ mice rescued their testicular defects (Fig. 8 D). H\&E and MVH staining indicated the number of tubules and spermatogonia increased after FTI administration (Fig. 8, E-G). 


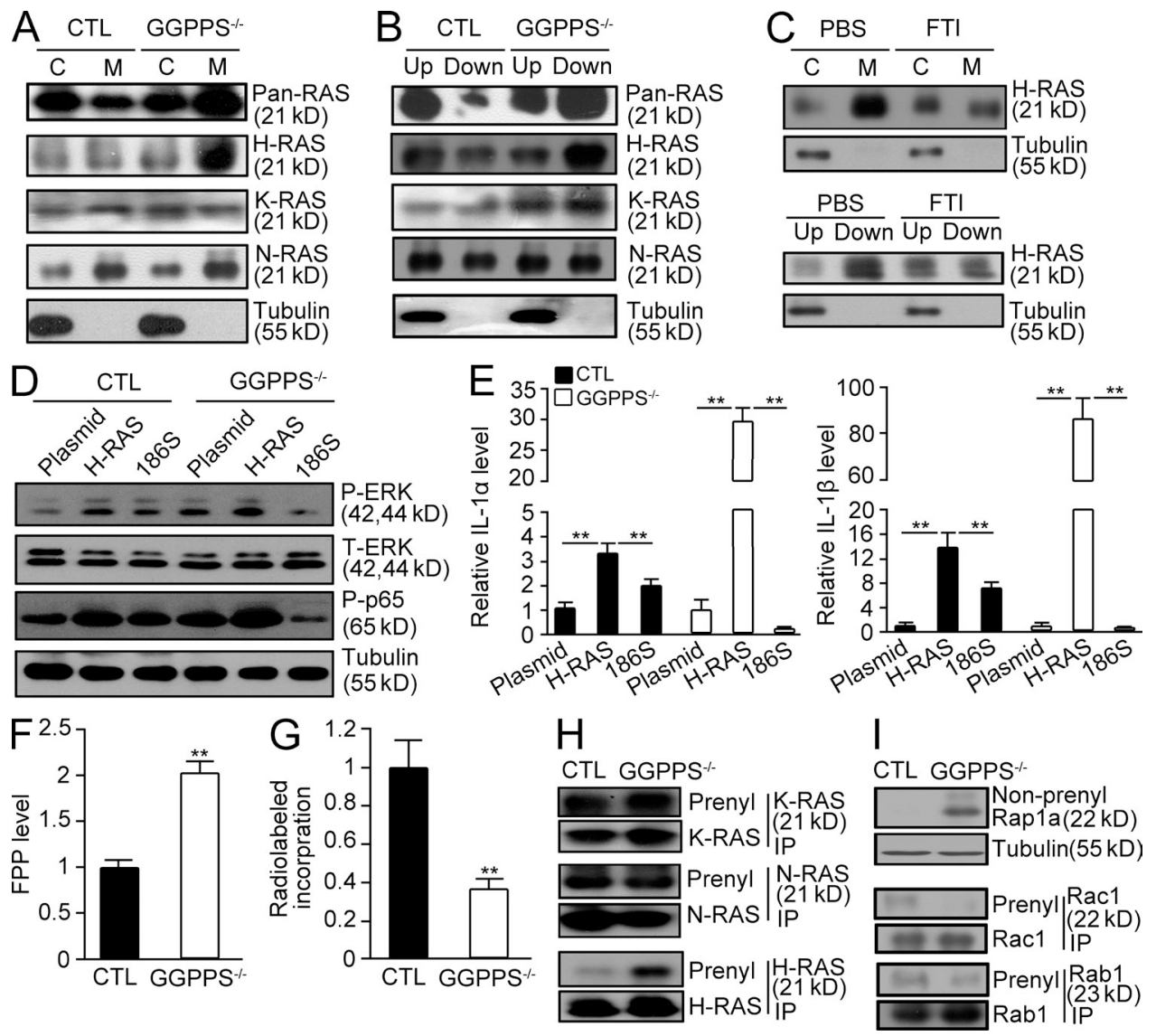

Figure 7. GGPPS deletion results in increased H-Ras farnesylation in Sertoli cells, leading to the spontaneous hyperinflammatory response in the testes. (A and B) The membrane association and prenylation of Ras proteins in GGPPS ${ }^{-1-}$ Sertoli cells were analyzed using membrane separation and Triton X-114 extraction methods, respectively. (C) The membrane association and prenylation of H-Ras in GGPPS-1- Sertoli cells after FTI treatment. (D) Erk1/2 and NF-KB activation (E) IL-1 $\alpha$ (left to right: ${ }^{* *}, P=0.000424 ;{ }^{* *}, P=0.0027 ;{ }^{* *} \mathrm{P}=0.00249 ;{ }^{* *}, \mathrm{P}=0.00227$ ) and IL-1 $\beta$ (left to right: ${ }^{* *}, \mathrm{P}=$ $0.00024 ;{ }^{* *}, P=0.0032 ;{ }^{* *}, P=0.000312 ;{ }^{* *}, P=0.0003$ ) expression level. (F) The FPP level in Sertoli cells detected with LC-MS method (**, P $=0.000118$ ). (G) Radiolabeled incorporation of FPP in GGPPS-deleted Sertoli cells (**, P = 0.00158). ( $\mathrm{H}$ and I) IP analysis of RAS prenylation of Ras family $(H)$ and Rap1a, Rac1, and Rabs. (I) The prenylation of N-Ras and K-Ras that can be either geranylgeranylated or farnesylated (H). The prenylation of Rap1a, Rac1, and Rabs that can only be geranylgeranylated (I). All of the groups of experimental animals contained a minimum of five mice. All of the data are representative of at least three replicates and are presented as the mean and SEM. ${ }^{*}, \mathrm{P}<0.05$, versus control; ${ }^{* *}, \mathrm{P}<0.005$, versus control.

EMCV challenge results in a mouse testis defect by inhibiting GGPPS expression and consequently altering protein prenylation

To determine whether the protein prenylation state is crucial to the immune response in testes with mumps infection-induced infertility, we used EMCV to attack the mouse testis in a similar manner to the human mumps virus. We observed that EMCV infection decreased GGPPS expression in mouse testis in a time-dependent manner (Fig. 9 A) due to the increase in $\mathrm{GpC}$ island methylation in the GGPPS promoter (Fig. 9, B and C). EMCV infection also enhanced $\mathrm{H}$-Ras prenylation (Fig. 9 D) and increased the expression of $I L-1 \alpha$ and $I L-1 \beta$ in Sertoli cells in a protein farnesylation-dependent manner (Fig. 9 E). $\mathrm{H} \& \mathrm{E}$ staining indicated that the seminiferous tubules were degenerated after the EMCV attack because of the augmentation of the inflammatory response (Fig. 9 F). However, when we administered GGPP in addition to the EMCV challenge, the testis defects of the mice were largely rescued, the sperm number was increased (Fig. $9 \mathrm{G}$ ) and infertility of the infected mice was recovered and 2 of 5 ECMV-attacked mice impregnated females after GGPP administration (Fig. 9 H). This result further supports our suggestion that protein prenylation in Sertoli cells is critical for spermatogenesis in mumps-infected mouse testes.

\section{DISCUSSION}

Orchitis, which can be an acute local or systemic infection (or which can even be characterized by a chronic asymptomatic inflammation of the testis) is one of the primary causes of male infertility (Schuppe et al., 2008). Orchitis can be caused by traumatic events, as well as by bacterial and viral infections, potentially occurring during adulthood or before puberty when the BTB is absent between the Sertoli cells. The most common cause of viral orchitis is a mumps infection, which most commonly occurs before puberty (Casella et al., 1997; Manson, 1990) but which may still result in adult infertility. 


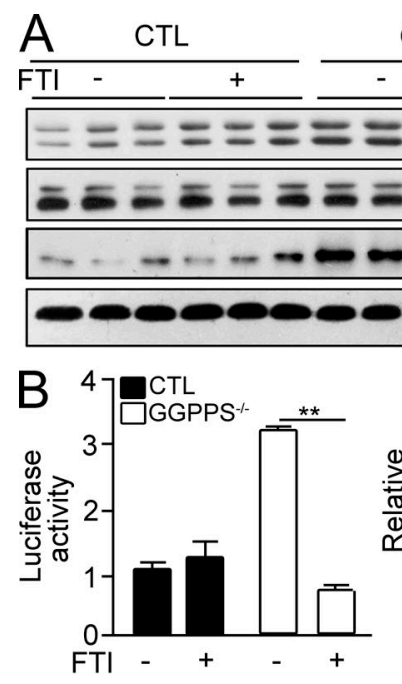

GGPPS $^{-1-}$
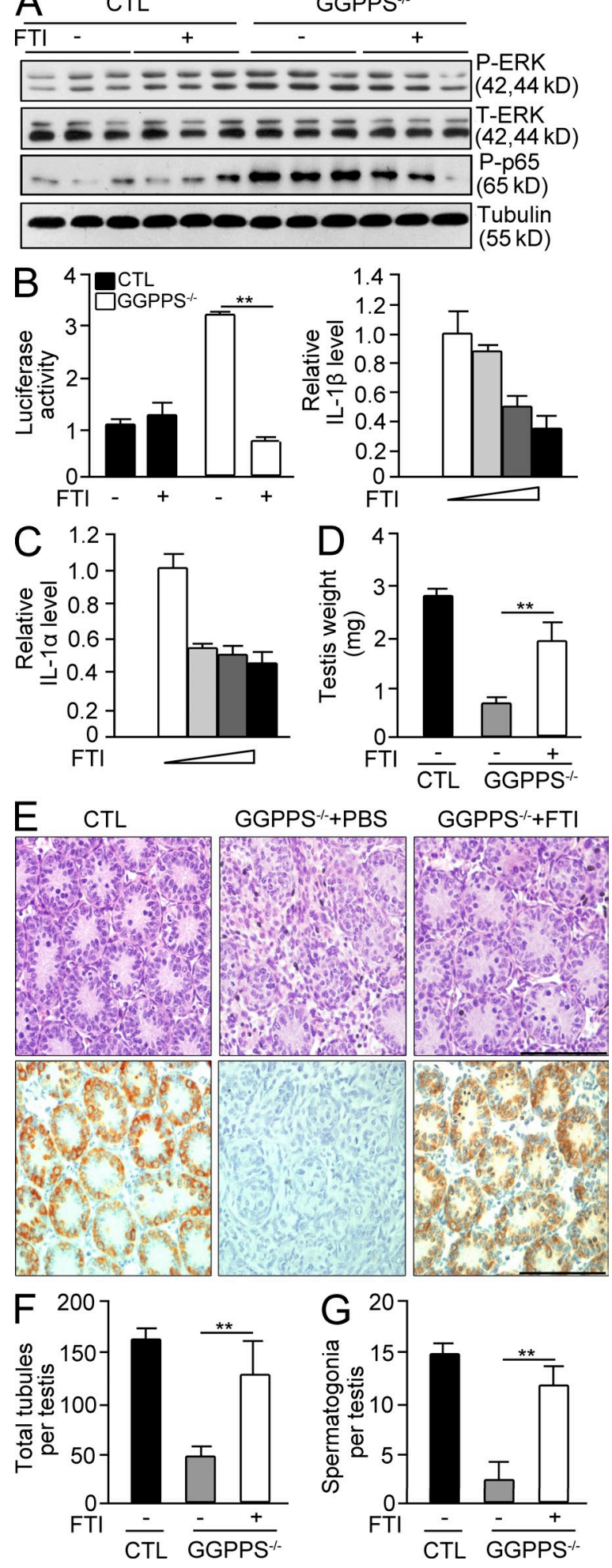

Figure 8. GGPPS deletion in Sertoli cell results in increased protein farnesylation, leading to increased inflammation in the testes.

(A) Erk1/2 and p65 activation was analyzed using Western blotting after FTI treatment. (B) NF- $\mathrm{KB}$ activation after FII administration was analyzed using a NF- $\mathrm{KB}$ reporter gene assay (**, $\mathrm{P}=0.000198)$. (C) The expression of $I L-1 \alpha$ and $I L-1 \beta$ in GGPPS $^{-1-}$ Sertoli cells after FI treatment $(5,10$, and
Virus can encode functional proteins to rapid inhibit host transcription after viral infection to secure its replication though altering chromatin structure (Mujtaba et al., 2008) or DNA methylation (Feng et al., 2010). The antiviral activity of host cell was inhibited after viral infection by methylating and subsequent down-regulating IFN- $\gamma$ production. We found that the promoter of GGPPS was also methylated and its expression was blocked by mumps and EMCV infection.

Using a cell-specific knockout of the GGPPS gene from mouse Sertoli cells, we were surprised to observe that the Sertoli cells remained intact, whereas spermatogonia died during the 3-5 d after birth. Further analysis suggested that GGPPS inactivation resulted in Sertoli cell synthesis and secretion of cytokines and chemokines via NF- $\mathrm{KB}$ and MAPK signaling pathway activation, augmenting the inflammatory response in the testis. There are two possible pathways by which inflammation could induce spermatogonia loss. First, the cytokines IL-6 and TNF that are released from Sertoli cells and other somatic cells can bind to their receptors on the surface of spermatogonia and induce apoptosis through an intracellular signal cascade (Theas et al., 2003; Guazzone et al., 2009; Yao et al., 2009). Second, other chemokines, such as G-CSF, CCL2 (MCP-1), CCL3 (MIP-1 $\alpha$ ), and CXCL2 (MIP-2 $\alpha$ ), which are released from Sertoli cells and other somatic cells, can recruit macrophages and stimulate proliferation of tissue-resident macrophages. Because there is no BTB between Sertoli cells at that stage, macrophages can very easily invade the testicular tubules and attack developing spermatogonium cells. Therefore, even if spermatogonia escape the cytokine attack during early postnatal stages, luminal resident macrophages could further block spermatogonium development after puberty in Sc-GGPPS ${ }^{-/-}$mice, resulting in a long-term effect on adult fertility. This observation can explain why a mumps infection during childhood occasionally leads to adult infertility.

The relationship between the mevalonate metabolic pathway and the immune response became known through the use of statins, which are HMG-CoA reductase inhibitors. Statins are widely used as cholesterol-lowering drugs and are also beneficial in the treatment of rheumatoid arthritis and autoimmune diseases (Greenwood et al., 2006; Paraskevas, 2008). Statins can block the production of mevalonate and, in turn, reduce the levels of both GGPP and FPP, the lipid substrates of the protein modification prenylation (Winter-Vann and Casey, 2005). Previous studies have indicated that statin acts as an antiinflammatory by inhibiting both farnesylation and geranylgeranylation (Greenwood et al., 2006; Paraskevas, 2008).

$20 \mu \mathrm{M} ; \mathrm{D}-\mathrm{G})$ Testis weight after intraperitoneal administration of FII into first postnatal day Sc-GGPPS ${ }^{-1-}$ mice at seventh postnatal day $\left({ }^{* *}, \mathrm{P}=\right.$ $0.00106 ; D)$. H\&E staining and MVH staining of testis (E), seminiferous tubules (**, $P=0.000343 ; F)$, and spermatogonia ( $\left.{ }^{*}, P=2.2 E-09\right)$ of testes (G). All of the groups of experimental animals contained a minimum of five mice. All of the data are representative of at least three replicates and are presented as the mean and SEM. ${ }^{*}, \mathrm{P}<0.05$, versus control; ${ }^{*}, \mathrm{P}<$ 0.005 , versus control. Bar, $100 \mu \mathrm{m}$. 

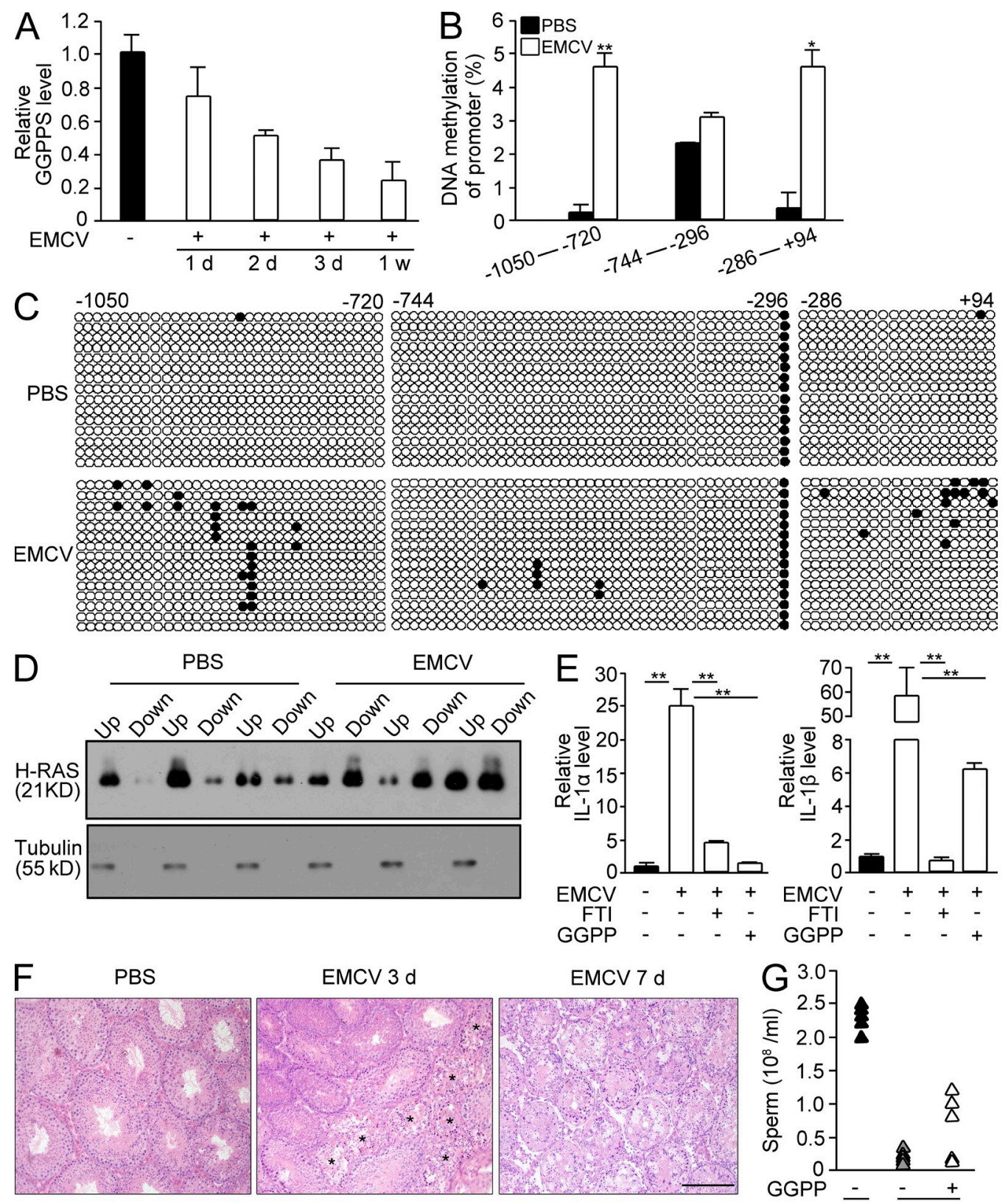

EMCV $7 \mathrm{~d}$
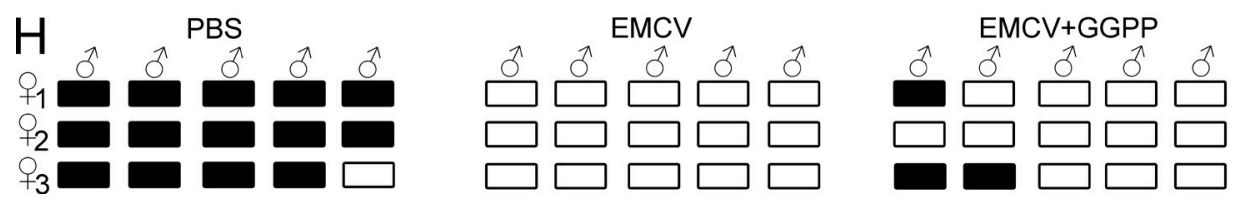

Figure 9. EMCV challenge results in a mouse testis defect due to altered protein prenylation by inhibiting GGPPS expression. (A) GGPPS expression in mouse testes after EMCV challenge over time. (B) The methylation level of CpG islands in GGPPS's promoter after EMCV infection ${ }^{* *}, \mathrm{P}=$ $\left.0.00487 ;{ }^{*}, P=0.0136\right)$. (C) The prenylation of $H$-Ras in Sertoli cells after EMCV infection. (D) The expression of $I L-1 \alpha$ (PBS versus EMCV, ${ }^{* *}, P=0.000339$; EMCV versus EMCV+FTI, ${ }^{* *}, P=0.000543, E M C V$ versus EMCV+GGPP, ${ }^{* *}, P=0.000344$ ) and $I L-1 \beta$ (PBS versus EMCV, ${ }^{* *}, P=0.00277 ;$ EMCV versus $\mathrm{EMCV}+\mathrm{FTI},{ }^{* *}, \mathrm{P}=0.00273$; EMCV versus EMCV+GGPP, $\left.{ }^{* *}, \mathrm{P}=0.003675\right)$ after EMCV infection after GGPP or FII administration. (E) H\&E staining after EMCV infection. Stars indicate the degenerated tubules. ( $F$ and G) Fertility after GGPP supplements into EMCV-challenged mice. Sperm number after GGPP administration (F) and pregnancy of mice after GGPP administration into EMCV-infected mice (G). (H) Pregnancy analysis of ECMV-attacked mice after GGPP administration. All of the groups of experimental animals contained a minimum of five mice. All of the data are representative of at least three replicates and are presented as the mean and SEM. ${ }^{*}, \mathrm{P}<0.05$, versus control; ${ }^{*}, \mathrm{P}<0.005$, versus control. Bar, $100 \mu \mathrm{m}$. 
This result has encouraged many scientists to investigate the possibility that inhibiting protein prenylation may be a strategy by which to treat inflammatory diseases. However, unexpectedly, an in vivo study by Khan et al. (2011) suggested that macrophage-specific GGTase-I deficiency resulted not in impaired inflammation but rather an augmented inflammatory response. Inactivating GGTase-I increased the production of ROS and cytokines and induced a severe inflammatory joint disease in mice. Contrary to expectations, GGTase-I inactivation did not disrupt the membrane association of the RHO proteins that are generally geranylgeranylated, and high levels of active GTP-bound RAC1 accumulated in the plasma membrane (Khan et al., 2011). The explanation for these results was that inhibiting geranylgeranylation blocked the binding of RHO family proteins to RHO-GAPs or RHO-GDI, inhibiting GTP hydrolysis and protein degradation, respectively.

The work of Khan et al. (2011) and our observations are supported by an earlier study by Mandey et al. (2006) that the inhibition of protein prenylation leads to a marked increase in lipopolysaccharide-stimulated IL-1 $\beta$ secretion. GGPP and mevalonic acid supplementation reversed higher IL-1 $\beta$ levels in patients with mevalonate kinase deficiency (MKD). When cells were treated with farnesyl transferase inhibitors, Rowell et al. (1997) demonstrated that Ki-Ras became geranylgeranylated in a dose-dependent manner. Recently, Weivoda and Hohl (2011) reported that FPP accumulated intracellularly when the GGPPS inhibitor DGBP was added to MC3T3-E1 preosteoblast cells. All of these results indicate that protein geranylgeranylation and farnesylation could be substituted for one another under certain extreme conditions in which one modification is completely inhibited.

In contrast to GGTase-I inactivation, a context in which GGPP synthesis is unaffected, GGPPS deletion resulted in the complete inhibition of GGPP production. However, as the mevalonate metabolic pathway progresses, the GGPPS substrate FPP may accumulate inside Sertoli cells, as is suggested by the in vitro results of Weivoda and Hohl (2011) and our observation. We observed that MAPK Erk1/2 was constitutively activated in Sc-GGPPS ${ }^{-/-}$Sertoli cells, suggesting that the Ras-Raf signaling pathway was functional despite the inhibition of the geranylgeranylation of RAS proteins. Proteins with the CaaX motif in their carboxyl termini can be modified by geranylgeranylation and/or farnesylation. We hypothesize that FPP accumulation and increased farnesylation may alter the protein prenylation state and disrupt the protein balance between geranylgeranylation and farnesylation. The prenylation of certain proteins that are primarily farnesylated, such as H-Ras, would be enhanced because of the accumulation of FPP after GGPPS inactivation. For proteins that can be either geranylgeranylated or farnesylated, such as N-Ras and K-Ras, the prenylation would remain unchanged or be slightly decreased. For proteins that can only be geranylgeranylated, such as Rabs, the prenylation would not be entirely blocked but only decreased (Fig. 7, H and I). This effect was observed because FPP can partially substitute for GGPP in the modification of these proteins. This hypothesis was confirmed by the detection of the plasma membrane association and prenylation of $\mathrm{H}-\mathrm{R} a \mathrm{~s}$, indicating that it was farnesylation that resulted in the prenylation of H-Ras. The increase in H-Ras farnesylation induces a downstream cascade, activating MAPK Erk1/2 and, in turn, $\mathrm{NF}-\kappa \mathrm{B}$ activation, augmenting the inflammatory reaction. Another possibility of the increase of H-Ras membrane association is that the disturbance of Rab1's prenylation may result in H-Ras activation. Rab proteins are involved in vesicular transport. Although the farnesylation partially restores the function of these proteins to support Sertoli cell survival and functionality, the intracellular membrane transport may be severely impaired in GGPPS-deleted cells which could potentially lead to altered membrane structure/dynamics that resulted in H-Ras being retained at the plasma membrane.

In summary, inactivating GGPPS in testicular Sertoli cells resulted in sustained activation of H-RAS proteins and a spontaneous hyperinflammation response in the early stage of testis development, during which no BTB is present between mouse Sertoli cells. Our results indicated that protein prenylation in Sertoli cells was critical for regulating the immune response in testis before puberty. This phenotype of GGPPS inactivation can mimic the insult, such as mumps infection, that Sertoli cells face during childhood and that can result in adulthood infertility.

\section{MATERIALS AND METHODS}

Study approval. For the use of clinical materials for research purposes, prior patient consent and approval were obtained from the Nanjing University and The Affiliated Drum Tower Hospital Board. The analysis of sperm concentration, motility, and morphology was performed following World Health Organization (WHO) criteria (1999). This clinical study was conducted according to the Declaration of Helsinki principles. Mice were housed in accordance with the regulations on mouse welfare and ethics of Nanjing University in groups with 12-h dark-light cycles and free access to food and water. The experimental animal facility has been accredited by AAALAC (Association for Assessment and Accreditation of Laboratory Animal Care International) and the IACUC (Institutional Animal Care and Use Committee) of Model Animal Research Center of Nanjing University approved all animal protocols used in this study.

Subjects. The 16 infertile male testis samples ( 9 patients with a history of mumps infection and 7 without) were collected from The Affiliated Drum Tower Hospital of Nanjing University in China. The donors were aged $20-30 \mathrm{yr}$ and lived in the Jiangsu area. All of the infertile male subjects were selected on the basis of comprehensive andrological testing, including the examination of medical history, physical examination, semen analyses, and hormone analyses (Hu et al., 2011).

Mice. We generated mice with Sertoli cell-specific GGPPS deletion by crossing AMH-Cre transgenic mice (Lécureuil et al., 2002) to homozygous floxed GGPPS mice. The littermates were used as controls. The knockout lines (129) were backcrossed a minimum of six generations to the C57BL/6 background, which was the background of the GGPPS-LoxP mice. Fertility and the weight of both the testes and the epididymis were not significantly different between heterozygous littermates (Hetz) mice and wild-type mice. Thus, we used the Hetz as controls (CTL) in the present study.The offspring genotyping was performed using PCR (the primers for the PCR and the qRT-PCR analyses are indicated in Table S1). The knockout efficiency was verified using qRT-PCR to detect GGPPS mRNA and Western blotting to detect GGPPS protein in isolated Sertoli cells. The procedure for isolating primary Sertoli cells was performed as previously described (Wang et al., 2006; Sun et al., 2010). 
Materials. GGPP (Sigma-Aldrich) was diluted in methanol. Geranylgeranyl transferase I inhibitor (GGTI-298; Sigma-Aldrich), and U0126 (Cell Signaling Technology) were diluted in DMSO. The farnesyl transferase inhibitor (FTI277; Sigma-Aldrich) was diluted in PBS. The bortezomib (Janssen-Cilag) was diluted in saline. The bortezomib $(3 \mathrm{mg} / \mathrm{kg})$ was intraperitoneally administered at $2-\mathrm{d}$ intervals, and the GGPP $(2 \mathrm{mg} / \mathrm{kg} /$ day $)$ and FTI $(40 \mathrm{mg} / \mathrm{kg} /$ day $)$ were intraperitoneally administered daily to Sc-GGPPS ${ }^{-1-}$ mice or EMCVinfected mice from the first postnatal day until sacrifice or mating. The tritium-labeled GGPP and FPP were obtained from American Radiolabeled Chemicals. The Ggtase-I and Ftase were from Millipore. The antibodies that were used for immunoblotting and immunoprecipitation included antibodies against Erk1/2, its phosphorylated form and phosphorylated p65 (S536) and were from Cell Signaling Technology. The GGPPS, pan-Ras, K-Ras-2B, H-Ras, N-Ras, RAC1, Rab1, Rap1a primary antibodies, and alkaline phosphatase-conjugated secondary antibodies were from Santa Cruz Biotechnology. The antibodies for the immunostaining analyses included antibodies against WT1 (Santa Cruz Biotechnology), MVH (Abcam) F4/80 (AbD Serotec), GGPPS (Santa Cruz Biotechnology) and p65 (Cell Signaling Technology). H-Ras-SaaX (Cys186 mutated to Ser186, H-Ras-S186) was generated using PCR-directed mutagenesis and verified by sequencing. H-Ras-S186 and wild-type H-RAS were amplified and subcloned into the pcDNA3.1 vector. The primers that were used are listed in Table S1. The plasmid was transfected into primary Sertoli cells using FuGENE-HD (Roche). The cells were collected after $48 \mathrm{~h}$ for additional assays. The plaque-isolated $\mathrm{D}$ variant of the EMCV virus was cultured in HeLa cells and stored at $-80^{\circ} \mathrm{C}$ until further use. The titer of this virus stock was determined using the plaque assay on HeLa cell cultures. EMCV (10 PFU) was administered into the testis of 8-wk-old mice, and the fertility assessment was performed 3 wk later.

Fertility assay and epididymal sperm assessment. The reproductive capacity was investigated by mating one male with three C57BL/ 6 females, as previously published (Chang et al., 2004). Bortezomib (3 mg/kg/day) was intraperitoneally administered into Sc-GGPPS ${ }^{-1-}$ mice from the first postnatal day to the age of $8 \mathrm{wk}$, and the mice were then subjected to the fertility assessment. GGPP $(2 \mathrm{mg} / \mathrm{kg}$ /day) was intraperitoneally administered into EMCV-infected 8-wk-old mice, and the mice were then subjected to the fertility assessment.

Histology, immunohistochemistry, immunofluorescence, and the TUNEL assay. For the H\&E staining, the testes were fixed in Bouin's fixative and then processed for paraffin-embedded sectioning. For the immunohistochemistry and immunofluorescence analyses, the primary antibodies were as follows: rabbit anti-GGPPS (1:50; Santa Cruz Biotechnology, Inc.), rabbit anti-MVH/DDX4 (1:100; Abcam), rabbit anti-WT1 (1:200; Santa Cruz Biotechnology, Inc.), rabbit anti-NF-кB p65 (1:50, Cell Signaling Technology), and rat anti-F4/80(1:300; AbD Serotec). We used an avidin-biotin complex (VECTASTAIN ABC kit) for the immunohistochemical analysis. For the immunofluorescent analysis, we used Alexa Fluor 488 or Alexa Fluor 594 (Invitrogen). Apoptosis was assessed using a florescent TUNEL kit (G3250; Promega).

Image processing. All of the images were visualized by fluorescent microscopy (BX51; Olympus) and captured using a DP71 camera that was controlled by image-Pro express software. The majority of the observations were performed using an Olympus UPlanFL $40 \times / 0.75 \mathrm{Ph} 2$ objective. The work temperature was $-10^{\circ} \mathrm{C}$. The images were processed for publication using Photoshop CS3 (Adobe Systems). The adjustment of brightness, contrast, and color balance were applied to every pixel in the image.

Sertoli cell isolation and cell culture. The isolation of the primary Sertoli cells was performed as previously described (Wang et al., 2006; Sun et al., 2010). Sertoli cells were cultured in DMEM/F12 medium (Sigma-Aldrich) that was supplemented with sodium bicarbonate $(1.2 \mathrm{mg} / \mathrm{ml})$, penicillin $(100 \mathrm{U} / \mathrm{ml})$, streptomycin $(100 \mathrm{mg} / \mathrm{ml})$, and $10 \%$ fetal calf serum (Life Technologies). The cells were maintained in a humidified atmosphere that contained
$5 \% \mathrm{CO}_{2}$ at $37^{\circ} \mathrm{C}$ for $24 \mathrm{~h}$. After incubation, the cells were treated with a hypotonic solution ( $20 \mathrm{mM}$ Tris, $\mathrm{pH}$ 7.4) for $1 \mathrm{~min}$ to remove the spermatogenic cells adhering to the Sertoli cells. After a 24-h culture, the Sertoli cells were collected for RNA and protein extraction or transfected and reseeded in plates for immunostaining. Otherwise, the medium was collected for coculture. For the cytokine array and ELISA, DMEM/F12 medium with 10\% fetal calf serum was replaced by nonserum medium, and the medium was collected after $24 \mathrm{~h}$ for the analysis. For the EMCV challenge, primary Sertoli cells were infected with $10 \mathrm{PFU} /$ well. The cultures without EMCV inoculation were used as control. The cells were collected after $24 \mathrm{~h}$ for the qRT-PCR analyses.

RNA extraction and gene expression, luciferase assay, and DNA methylation analyses. RNA was extracted from patients, mouse testes, and primary Sertoli cells (MasterPrep-24; Haichuan Biotech) for qRT-PCR analyses. SYBR Green Master Mix (Takara Bio Inc.) was used in an ABI 7300 system (Applied Biosystems). The primers that were used are listed in Table S1. A promoter that contained NF- $\mathrm{\kappa B}-$ binding element constructs was transfected into primary Sertoli cells with Fugene-HD (Roche) as previously published (Yu et al., 2011). For the analysis of the promoter methylation patterns, the DNA that was isolated from the testes was sodium bisulfite-treated using an EpiTect Bisulfite kit (QIAGEN). The PCR products of bisulfite-treated genomic DNA were cloned into the pMD-19T (Takara) vector using the TOPO TA cloning kit (Takara Bio Inc.), and five to six clones from each sample were picked for sequencing analysis. The primers that were used are listed in Table S1.

Cell lysates, immunoprecipitation, and immunoblotting. The cells were washed in ice-cold PBS and harvested with RIPA buffer that contained vanadate and protease inhibitors. The lysates $(400 \mathrm{mg})$ were immunoprecipitated first with anti-pan-RAS antibodies (Santa Cruz Biotechnology, Inc.) and then with agarose bead-coupled protein A (GE Healthcare). For the immunoblotting, the cell and tissue protein extracts (250 $\mathrm{mg}$ total protein) were boiled in loading buffer, separated by $10 \%$ SDS-PAGE, and then transferred onto polyvinylidene difluoride membranes (Roche). The membranes were incubated overnight with the appropriate primary antibodies. The bound antibodies were then visualized using alkaline phosphatase-conjugated secondary antibodies. The intensities of the bands were quantified using the National Institutes of Health (NIH) Image 1.62 program.

Microarray analysis and confirmation. mRNA from primary Sertoli cells on the third postnatal day mice was harvested ( $n=30$ mice per group) and hybridized to the GeneChip microarray (Affymetrix). The data analysis was performed using GeneSpring GX 11.0 (Agilent Technologies) Partek GS 6.5 software. We performed hierarchical clustering using MATLAB (MathWorks). The microarray data have been deposited in the Gene Expression Omnibus database with the accession no. GSE35755.

The microarray data were confirmed using a mouse cytokine antibody array (RayBiotech). Densitometric analysis of the array was performed using NIH ImageJ software. The concentrations of chemokines and cytokines that were released into the supernatant from primary Sertoli cells were measured using specific ELISAs against TNF, IL-1 $\alpha$, CCL2, and CCL5 (R\&D Systems).

Prenylation and membrane association measurements. Protein prenylation was measured as described previously (Shen et al., 2011). In brief, Sertoli cells with the indicated treatment were lysed in $500 \mu \mathrm{l}$ lysis buffer. The total protein concentration was diluted to $1 \mathrm{mg} / \mathrm{ml}$ and partitioned with same volume of $4 \%$ Triton X-114 for $5 \mathrm{~min}$ at $37^{\circ} \mathrm{C}$ to solubilize and fractionate the lipid-rich cell membrane. The aqueous upper phase contains enriched intracellular protein, and the organic lower phase contains highly enriched membraneassociated proteins. To determine the membrane association of the proteins, a subcellular membrane fractionation of the treated Sertoli cells was prepared as previously described (Sjogren et al., 2007). In brief, the cell pellets were lysed and homogenized with ice-cold Dounce tissue homogenizer, and the lysate was centrifuged at $100,000 \mathrm{~g}$ for $30 \mathrm{~min}\left(4^{\circ} \mathrm{C}\right)$. The supernatant $(\mathrm{S} 100)$ represents the 
cytosolic fraction, and the pellet (P100) represents the membrane fraction. All of the aforementioned samples were subjected to immunoprecipitation and Western blot detection of the proteins that were present at different portions.

HPLC-MS/MS measurement of FPP and GGPP. The HPLC system consisted of two LC-30A ultra-high pressure gradient pumps, a vacuum degasser (DGU-20A5), and an autosampler (SIL-30AC). Column temperature was maintained at $20^{\circ} \mathrm{C}$. The samples were injected onto a $3 \times 100-\mathrm{mm}$ Inert Sustain C18 column, $3 \mu \mathrm{m}$ diameter. The intermediates of the isoprenoid biosynthesis pathway, FPP and GGPP were separated by a linear gradient between solution A $(0.1 \% \mathrm{NH} 3 \times \mathrm{H} 2 \mathrm{O})$ and solution $\mathrm{B}(100 \%$ Acetonitrile $)$. The gradient was as follows: $0-1 \mathrm{~min}: 5 \% \mathrm{~B}$ to $5 \% \mathrm{~B} ; 1-3 \mathrm{~min}: 5 \% \mathrm{~B}$ to $80 \%$; 3-5 min: $80 \%$ B to $80 \%$ B; $5-5.1$ min: $80 \%$ B to $5 \%$ B; $5.1-6.5$ min: equilibration with $5 \% \mathrm{~B}$. The flow rate was set at $0.4 \mathrm{ml} / \mathrm{min}$. For each analysis, $2 \mu \mathrm{l}$ of sample was injected onto the column, and the total analysis time, including the equilibration, was $6.5 \mathrm{~min}$. A LCMS-8040 (Shimadzu Corporation, Kyoto, Japan) was used in the negative electrospray ionization mode. Nitrogen was used as the nebulizing gas, and argon was used as the collision gas. The intermediates, FPP and GGPP were detected with the mass spectrometer in Multiple Reaction Monitoring (MRM) mode.The MRM transitions for FPP/GGPP and external standards were as follows: FPP (parent ion $\mathrm{m} / \mathrm{z}: 381.05$ to product ion $\mathrm{m} / \mathrm{z}$ : 79.10); GGPP (parent ion $\mathrm{m} / \mathrm{z}: 449.15$ to product ion $\mathrm{m} / \mathrm{z}: 79.20$ ).

Tritium-labeled GGPP and FPP incorporation. To assay tritium-labeled GGPP and FPP incorporation, the primary Sertoli cells were resuspended in a buffer that contained $50 \mathrm{mM}$ Tris- $\mathrm{HCl}, 1 \mathrm{M} \mathrm{MgCl} 2,10 \mathrm{mM}$ DTT, $1 \mathrm{mM}$ PMSF, $2.5 \mathrm{mM} \mathrm{NaF}$, and $1 \mathrm{mM} \mathrm{Na} 2 \mathrm{VO}$. The resuspended cells were sonicated and centrifuged at $21,000 \mathrm{~g}$ for $20 \mathrm{~min}$. The supernatants $(600 \mu \mathrm{g})$ were incubated with $50 \mathrm{ng}$ recombinant human GGTase-I or Ftase (Millipore) and $6 \mu \mathrm{Ci} 3 \mathrm{H}-\mathrm{GGPP}$ or $6 \mu \mathrm{Ci} 3 \mathrm{H}-\mathrm{FPP}$ (American Radiolabeled Chemicals Inc.) for $1 \mathrm{~h}$ at $30^{\circ} \mathrm{C}$ (Khan et al., 2011). After the incubation, the reactions were ceased by the addition of $500 \mathrm{ml}$ of $4 \%$ SDS and precipitated directly with $500 \mathrm{ml} 30 \%$ trichloroacetic acid for at least $20 \mathrm{~min}$. The product was trapped in a No. 31 fiber filter (Schleicher \& Schuell). The filters were washed with 2\% SDS/6\% TCA ( 3 washes, $2 \mathrm{ml}$ ), followed by washes with 6\% TCA (3 washes, $2 \mathrm{ml}$ ) and vacuum filtration. The bound radioactivity was determined by scintillation counting (Thissen and Casey, 1996). The higher incorporation of tritium-labeled GGPP and FPP represents lower protein prenylation level in Sertoli cells.

Data analysis. All of the data are presented as the mean \pm SEM. The data were analyzed using a one-way ANOVA followed by Fisher's LSD post-hoc test. The calculations were performed using SPSS/Windows version $12.5 \mathrm{~S}$ statistical package (SPSS). In all cases, statistical significance is displayed as $\mathrm{P}<0.05$ (one asterisk) or $\mathrm{P}<0.005$ (two asterisks).

Online supplemental material. Table S1 depicts the primer sequences that were used for the qRT-PCR, H-RAS expression vector construction, and DNA methylation sequencing. Online supplemental material is available at http://www.jem.org/cgi/content/full/jem.20121806/DC1.

This work was supported by National Basic Research Program of China. Grant 2009CB91703 was awarded to Professor Chao-Jun Li and 2013CB947902 was awarded to Professor Qing-Hua Shi. National Natural Science Foundation of China grant 31271540 was awarded to Professor Chao-Jun Li.

The authors have no conflicting financial interests.

\section{Submitted: 10 August 2012}

Accepted: 6 June 2013

\section{REFERENCES}

Adamopoulos, D.A., D.M. Lawrence, P. Vassilopoulos, P.A. Contoyiannis, and G.I. Swyer. 1978. Pituitary-testicular interrelationships in mumps orchitis and other viral infections. BMJ. 1:1177-1180. http://dx.doi.org/ 10.1136/bmj.1.6121.1177

Andrejeva, J., K.S. Childs, D.F. Young, T.S. Carlos, N. Stock, S. Goodbourn, and R.E. Randall. 2004. The V proteins of paramyxoviruses bind the
IFN-inducible RNA helicase, mda-5, and inhibit its activation of the IFN- $\beta$ promoter. Proc. Natl. Acad. Sci. USA. 101:17264-17269. http:// dx.doi.org/10.1073/pnas.0407639101

Ashby, M.N. 1998. CaaX converting enzymes. Curr. Opin. Lipidol. 9:99102. http://dx.doi.org/10.1097/00041433-199804000-00004

Bertschat, F.L., and M. Alexander. 1981. [Infertility after mumps orchitis (author's transl)]. Munch. Med. Wochenschr. 123:606-608.

Boström, K. 1968. Patho-anatomical findings in a case of mumps with pancreatitis, myocarditis, orchitis, epididymitis and seminal vesiculitis. Virchows Arch. A Pathol. Pathol. Anat. 344:111-118. http://dx.doi.org/10.1007/ BF00544642

Casella, R., B. Leibundgut, K. Lehmann, and T.C. Gasser. 1997. Mumps orchitis: report of a mini-epidemic. J. Urol. 158:2158-2161. http://dx .doi.org/10.1016/S0022-5347(01)68186-2

Chang, C., Y.T. Chen, S.D. Yeh, Q. Xu, R.S. Wang, F. Guillou, H. Lardy, and S. Yeh. 2004. Infertility with defective spermatogenesis and hypotestosteronemia in male mice lacking the androgen receptor in Sertol cells. Proc. Natl. Acad. Sci. USA. 101:6876-6881. http://dx.doi.org/10 $.1073 /$ pnas. 0307306101

Chen, B.D., C.R. Clark, and T.H. Chou. 1988. Granulocyte/macrophage colony-stimulating factor stimulates monocyte and tissue macrophage proliferation and enhances their responsiveness to macrophage colonystimulating factor. Blood. 71:997-1002.

Clemens, M.J., J.W.B. Hershey, A.C. Hovanessian, B.C. Jacobs, M.G. Katze, R.J. Kaufman, P. Lengyel, C.E. Samuel, G.C. Sen, and B.R.G. Williams. 1993. PKR: proposed nomenclature for the RNA-dependent protein kinase induced by interferon. J. Interferon Res. 13:241. http:// dx.doi.org/10.1089/jir.1993.13.241

Dugan, J.M., and C.M. Allen. 1995. Changes in protein prenylation and prenyltransferase activity in the rat seminiferous epithelium during early stages of spermatogenesis. Biol. Reprod. 53:958-973. http://dx.doi.org/ 10.1095/biolreprod53.4.958

Fahey, T.J. III, K.J. Tracey, P. Tekamp-Olson, L.S. Cousens, W.G. Jones, G.T. Shires, A. Cerami, and B. Sherry. 1992. Macrophage inflammatory protein 1 modulates macrophage function. J. Immunol. 148:2764-2769.

Fallarino, F., G. Luca, M. Calvitti, F. Mancuso, C. Nastruzzi, M.C. Fioretti, U. Grohmann, E. Becchetti, A. Burgevin, R. Kratzer, et al. 2009. Therapy of experimental type 1 diabetes by isolated Sertoli cell xenografts alone. J. Exp. Med. 206:2511-2526. http://dx.doi.org/10.1084/jem.20090134

Feng, Q., J.E. Stern, S.E. Hawes, H. Lu, M. Jiang, and N.B. Kiviat. 2010. DNA methylation changes in normal liver tissues and hepatocellular carcinoma with different viral infection. Exp. Mol. Pathol. 88:287-292. http://dx.doi.org/10.1016/j.yexmp.2010.01.002

Fijak, M., and A. Meinhardt. 2006. The testis in immune privilege. Immunol. Rev. 213:66-81. http://dx.doi.org/10.1111/j.1600-065X.2006.00438.x

Gordon, S., and P.R. Taylor. 2005. Monocyte and macrophage heterogeneity. Nat. Rev. Immunol. 5:953-964. http://dx.doi.org/10.1038/nri1733

Greenwood, J., L. Steinman, and S.S. Zamvil. 2006. Statin therapy and autoimmune disease: from protein prenylation to immunomodulation. Nat. Rev. Immunol. 6:358-370. http://dx.doi.org/10.1038/nri1839

Griswold, M.D. 1998. The central role of Sertoli cells in spermatogenesis. Semin. Cell Dev. Biol. 9:411-416. http://dx.doi.org/10.1006/scdb .1998 .0203

Guazzone, V.A., P. Jacobo, M.S. Theas, and L. Lustig. 2009. Cytokines and chemokines in testicular inflammation: A brief review. Microsc. Res. Tech. 72:620-628. http://dx.doi.org/10.1002/jemt.20704

Hu, Z., Y. Xia, X. Guo, J. Dai, H.G. Li, H. Hu, Y. Jiang, F. Lu, Y. Wu, $\mathrm{X}$. Yang, et al. 2011. A genome-wide association study in Chinese men identifies three risk loci for non-obstructive azoospermia. Nat. Genet. 44:183-186. http://dx.doi.org/10.1038/ng.1040

Kawai, T., and S. Akira. 2006. Innate immune recognition of viral infection. Nat. Immunol. 7:131-137. http://dx.doi.org/10.1038/ni1303

Khan, O.M., M.X. Ibrahim, I.M. Jonsson, C. Karlsson, M. Liu, A.K.M Sjogren, F.J. Olofsson, M. Brisslert, S. Andersson, C. Ohlsson, et al. 2011. Geranylgeranyltransferase type I (GGTase-I) deficiency hyperactivates macrophages and induces erosive arthritis in mice. J. Clin. Invest. 121:628-639. http://dx.doi.org/10.1172/JCI43758

Kondo,Y.,Y. Kanai, M. Sakamoto, M. Mizokami, R. Ueda, and S. Hirohashi. 2000. Genetic instability and aberrant DNA methylation in chronic hepatitis 
and cirrhosis - A comprehensive study of loss of heterozygosity and microsatellite instability at 39 loci and DNA hypermethylation on $8 \mathrm{CpG}$ islands in microdissected specimens from patients with hepatocellular carcinoma. Hepatology. 32:970-979. http://dx.doi.org/10.1053/jhep .2000 .19797

Korbutt, G.S., J.F. Elliott, and R.V. Rajotte. 1997. Cotransplantation of allogeneic islets with allogeneic testicular cell aggregates allows long-term graft survival without systemic immunosuppression. Diabetes. 46:317322. http://dx.doi.org/10.2337/diabetes.46.2.317

Korbutt, G.S., W.L. Suarez-Pinzon, R.F. Power, R.V. Rajotte, and A Rabinovitch. 2000. Testicular Sertoli cells exert both protective and destructive effects on syngeneic islet grafts in non-obese diabetic mice. Diabetologia. 43:474-480. http://dx.doi.org/10.1007/s001250051331

Lécureuil, C., I. Fontaine, P. Crepieux, and F. Guillou. 2002. Sertoli and granulosa cell-specific Cre recombinase activity in transgenic mice. Genesis. 33:114-118. http://dx.doi.org/10.1002/gene.10100

Luster, A.D. 1998. Chemokines-chemotactic cytokines that mediate inflammation. N. Engl. J. Med. 338:436-445. http://dx.doi.org/10.1056/ NEJM199802123380706

Mandey, S.H.L., L.M. Kuijk, J. Frenkel, and H.R. Waterham. 2006. A role for geranylgeranylation in interleukin-1 $\beta$ secretion. Arthritis Rheum. 54:3690-3695. http://dx.doi.org/10.1002/art.22194

Manson, A.L. 1990. Mumps orchitis. Urology. 36:355-358. http://dx.doi .org/10.1016/0090-4295(90)80248-L

Mantovani, A., P. Allavena, and A. Sica. 2004. Tumour-associated macrophages as a prototypic type II polarised phagocyte population: role in tumour progression. Eur. J. Cancer. 40:1660-1667. http://dx.doi.org/ 10.1016/j.ejca.2004.03.016

Mikovits, J.A., H.A. Young, P. Vertino, J.P.J. Issa, P.M. Pitha, S. TurcoskiCorrales, D.D. Taub, C.L. Petrow, S.B. Baylin, and F.W. Ruscetti. 1998. Infection with human immunodeficiency virus type 1 upregulates DNA methyltransferase, resulting in de novo methylation of the gamma interferon (IFN-gamma) promoter and subsequent downregulation of IFN-gamma production. Mol. Cell. Biol. 18:5166-5177.

Mital, P., G. Kaur, and J.M. Dufour. 2010. Immunoprotective sertoli cells: making allogeneic and xenogeneic transplantation feasible. Reproduction. 139:495-504. http://dx.doi.org/10.1530/REP-09-0384

Mujtaba, S., K.L. Manzur,J.R. Gurnon, M. Kang, J.L.Van Etten, and M.M. Zhou. 2008. Epigenetic transcriptional repression of cellular genes by a viral SET protein. Nat. Cell Biol. 10:1114-1122. http://dx.doi.org/10.1038/ncb1772

Neels, J.G., and J.M. Olefsky. 2006. Inflamed fat: what starts the fire? J. Clin. Invest. 116:33-35. http://dx.doi.org/10.1172/JCI27280

Paraskevas, K.I. 2008. Statin treatment for rheumatoid arthritis: a promising novel indication. Clin. Rheumatol. 27:281-287. http://dx.doi.org/ 10.1007/s10067-007-0806-8

Riccioli, A., D. Starace, R. Galli, A. Fuso, S. Scarpa, F. Palombi, P. De Cesaris, E. Ziparo, and A. Filippini. 2006. Sertoli cells initiate testicular innate immune responses through TLR activation. J. Immunol. 177:7122-7130.

Rowell, C.A., J.J. Kowalczyk, M.D. Lewis, and A.M. Garcia. 1997. Direct demonstration of geranylgeranylation and farnesylation of Ki-Ras in vivo. J. Biol. Chem. 272:14093-14097. http://dx.doi.org/10.1074/jbc.272.22.14093

Schuppe, H.C., A. Meinhardt, J.P. Allam, M. Bergmann, W. Weidner, and G. Haidl. 2008. Chronic orchitis: a neglected cause of male infertility? Andrologia. 40:84-91. http://dx.doi.org/10.1111/j.1439-0272.2008.00837.x
Scott Reid, T., K.L. Terry, P.J. Casey, and L.S. Beese. 2004. Crystallographic analysis of CaaX prenyltransferases complexed with substrates defines rules of protein substrate selectivity. J. Mol. Res. 343:417-433. http:// dx.doi.org/10.1016/j.jmb.2004.08.056

Shen, N., X. Yu, F.Y. Pan, X. Gao, B. Xue, and C.J. Li. 2011. An early response transcription factor, Egr-1, enhances insulin resistance in type 2 diabetes with chronic hyperinsulinism. J. Biol. Chem. 286:14508-14515. http://dx.doi.org/10.1074/jbc.M110.190165

Sjogren, A.K., K.M.E. Andersson, M. Liu, B.A. Cutts, C. Karlsson, A.M. Wahlstrom, M. Dalin, C. Weinbaum, P.J. Casey, A. Tarkowski, et al. 2007. GGTase-I deficiency reduces tumor formation and improves survival in mice with K-RAS-induced lung cancer. J. Clin. Invest. 117:1294-1304. http://dx.doi.org/10.1172/JCI30868

Starace, D., R. Galli, A. Paone, P. De Cesaris, A. Filippini, E. Ziparo, and A. Riccioli. 2008. Toll-like receptor 3 activation induces antiviral immune responses in mouse sertoli cells. Biol. Reprod. 79:766-775. http://dx.do .org/10.1095/biolreprod.108.068619

Sun, B., N. Qi, T. Shang, H. Wu, T. Deng, and D. Han. 2010. Sertoli cellinitiated testicular innate immune response through toll-like receptor3 activation is negatively regulated by Tyro3, Axl, and mer receptors. Endocrinology. 151:2886-2897. http://dx.doi.org/10.1210/en.2009-1498

Theas, S., C. Rival, and L. Lustig. 2003. Germ cell apoptosis in autoimmune orchitis: involvement of the Fas-FasL system. Am. J. Reprod. Immunol. 50:166-176. http://dx.doi.org/10.1034/j.1600-0897.2003.00074.x

Thissen, J.A., and P.J. Casey. 1996. Kinetics of protein farnesyltransferase: sigmoidal vs hyperbolic behavior as a function of assay conditions. Anal. Biochem. 243:80-85. http://dx.doi.org/10.1006/abio.1996.0484

Wang, H., H. Wang, W. Xiong, Y. Chen, Q. Ma, J. Ma, Y. Ge, and D. Han. 2006. Evaluation on the phagocytosis of apoptotic spermatogenic cells by Sertoli cells in vitro through detecting lipid droplet formation by Oil Red O staining. Reproduction. 132:485-492. http://dx.doi .org/10.1530/rep.1.01213

Weivoda, M.M., and R.J. Hohl. 2011. The effects of direct inhibition of geranylgeranyl pyrophosphate synthase on osteoblast differentiation. J. Cell. Biochem. 112:1506-1513. http://dx.doi.org/10.1002/jcb.23087

Werner, C.A. 1950. Mumps orchitis and testicular atrophy; a factor in male sterility. Ann. Intern. Med. 32:1075-1086. http://dx.doi.org/10.7326/ 0003-4819-32-6-1075

Winter-Vann, A.M., and P.J. Casey. 2005. Post-prenylation-processing enzymes as new targets in oncogenesis. Nat. Rev. Cancer. 5:405-412. http://dx.doi.org/10.1038/nrc1612

Yao, P.L., Y.C. Lin, and J.H. Richburg. 2009. TNF alpha-mediated disruption of spermatogenesis in response to Sertoli cell injury in rodents is partially regulated by MMP2. Biol. Reprod. 80:581-589. http://dx.doi .org/10.1095/biolreprod.108.073122

Yoneyama, M., M. Kikuchi, T. Natsukawa, N. Shinobu, T. Imaizumi, M. Miyagishi, K. Taira, S. Akira, and T. Fujita. 2004. The RNA helicase RIG-I has an essential function in double-stranded RNA-induced innate antiviral responses. Nat. Immunol. 5:730-737. http://dx.doi.org/ 10.1038/ni1087

Yu, X., N. Shen, M.L. Zhang, F.Y. Pan, C. Wang, W.P. Jia, C. Liu, Q. Gao, X. Gao, B. Xue, and C.J. Li. 2011. Egr-1 decreases adipocyte insulin sensitivity by tilting PI3K/Akt and MAPK signal balance in mice. EMBO J. 30:3754-3765. http://dx.doi.org/10.1038/emboj.2011.277 